\title{
Spatially distributed characterization of soil-moisture dynamics using travel-time distributions
}

\author{
Falk Heße $^{1}$, Matthias Zink ${ }^{1}$, Rohini Kumar ${ }^{1}$, Luis Samaniego ${ }^{1}$, and Sabine Attinger ${ }^{1,2}$ \\ ${ }^{1}$ Department of Computational Hydrosystems, UFZ - Helmholtz Centre for Environmental Research, Leipzig, Germany \\ ${ }^{2}$ Institute of Geosciences, Faculty for Chemistry and Earth Sciences, Friedrich-Schiller-University Jena, Jena, Germany \\ Correspondence to: Falk Heße (falk.hesse@ufz.de)
}

Received: 13 May 2016 - Published in Hydrol. Earth Syst. Sci. Discuss.: 30 May 2016

Revised: 12 October 2016 - Accepted: 14 October 2016 - Published: 27 January 2017

\begin{abstract}
Travel-time distributions are a comprehensive tool for the characterization of hydrological system dynamics. Unlike the streamflow hydrograph, they describe the movement and storage of water within and throughout the hydrological system. Until recently, studies using such travel-time distributions have generally either been applied to lumped models or to real-world catchments using available time series, e.g., stable isotopes. Whereas the former are limited in their realism and lack information on the spatial arrangements of the relevant quantities, the latter are limited in their use of available data sets. In our study, we employ the spatially distributed mesoscale Hydrological Model (mHM) and apply it to a catchment in central Germany. Being able to draw on multiple large data sets for calibration and verification, we generate a large array of spatially distributed states and fluxes. These hydrological outputs are then used to compute the travel-time distributions for every grid cell in the modeling domain. A statistical analysis indicates the general soundness of the upscaling scheme employed in mHM and reveals precipitation, saturated soil moisture and potential evapotranspiration as important predictors for explaining the spatial heterogeneity of mean travel times. In addition, we demonstrate and discuss the high information content of mean travel times for characterization of internal hydrological processes.
\end{abstract}

\section{Introduction}

The description of transport of both water and dissolved contaminants in catchments is a challenging subject due to the high heterogeneity of the subsurface properties that govern their fate (Dagan, 1989). This heterogeneity, combined with a limited knowledge about the subsurface, results in high degrees of uncertainty. As a result, stochastic methods are often applied, where the relevant processes are modeled as being random (Dagan, 1986; Rubin, 2003). Among these methods, a powerful tool is the use of travel-time distributions (TTDs), where storage and transport in the catchment are modeled from a Lagrangian perspective (Rinaldo and Marani, 1987; Rinaldo et al., 1989). This means that the catchment itself, or meaningful parts of it, is treated as a control volume (CV). The spatially complex array of different flow paths inside this CV is ignored and only inlet and outlet fluxes are used for the analysis (Botter et al., 2010; Rinaldo et al., 2011; Botter, 2012). This observation-based description of catchment dynamics makes TTDs a very robust tool. Although the application of TTDs goes back many decades (Danckwerts, 1953; Niemi, 1977), recent developments have strongly improved their theoretical foundations, turning them into a versatile and coherent tool to characterize catchment dynamics (Bertuzzo et al., 2013; Benettin et al., 2015a; Rinaldo et al., 2015; Porporato and Calabrese, 2015). Owing to this progress, McMillan et al. (2012) and McDonnell and Beven (2014) have opined that TTDs should be used routinely for hydrological model calibration, a notion that has been picked up with tremendous speed (Windhorst et al., 2014; Vereecken et al., 2015; McGuire and McDonnell, 2015). Parallel to that, Kitanidis (2015) has recently pointed out that the key to subsurface characterization is to use all available information. From this information-centered perspective, using TTDs has several advantages. First, the travel-time behavior is controlled by different factors than the hydrograph response. Whereas the latter relates rainfall- 
runoff events, the former relates rainfall-runoff water (McDonnell and Beven, 2014; Birkel and Soulsby, 2015). Second, spatially distributed tracer experiments may dramatically increase the information content available for catchment characterization (Birkel and Soulsby, 2015).

These advantages have led to a steady increase in both applied and theoretical studies using TTDs for the description of catchment dynamics. Applied studies here means that data from real-world sites are used (McGuire et al., 2005; Cardenas, 2007; Broxton et al., 2009; Tetzlaff et al., 2011; Dunn et al., 2012; Hrachowitz et al., 2013, 2015; Harman, 2015). Compared to theoretical studies, the data do not suffer from model errors or other conceptual limitations, but are often limited in amount (typically limited to a few years only, although Hrachowitz et al. (2009) used time series of up to 17 years) and variety (only a limited number of data types are available). As a result, such studies might fail to find long-term trends, establish connections between traveltime behavior and specific catchment properties or investigate the impact of certain hydraulic regimes that only occur rarely (e.g., extreme drought or storm events). The second category are theoretical studies that either use a very simplified computational model to focus on specific questions (Rinaldo et al., 2006; Duffy, 2010; Botter et al., 2010; van der Velde et al., 2012; Benettin et al., 2015a; Porporato and Calabrese, 2015) or employ more realistic hydrological models that provide a large data set typically not available in realworld sites (Sayama and McDonnell, 2009; Fenicia et al., 2010; McMillan et al., 2012). Such theoretical studies allow a more thorough and detailed analysis of the involved processes and their interdependence may suffer from an oversimplified model setup for influx and outflux generation.

Our study falls into the latter category since we use a hydrological model, i.e., the mesoscale Hydrological Model (mHM) (Samaniego et al., 2010a; Kumar et al., 2013a), to generate the fluxes and states for the analysis. Using detailed data of precipitation, land cover, morphology and soil type as inputs, mHM is able to provide continuous simulations of spatially distributed fluxes (e.g., groundwater recharge or evapotranspiration) and states (e.g., soil moisture) as outputs. By employing mHM, which is a spatially distributed hydrological model, we are, however, able to go beyond prior studies to a spatially distributed traveltime analysis.

As a case study, we use a ca. $1000 \mathrm{~km}^{2}$ catchment in central Germany for which detailed morphological and climatological data are available to parameterize mHM. In addition, the chosen catchment is located in the Hainich Critical Zone Exploratory, a comprehensive monitoring network used within Collaborative Research Center AquaDiva (Küsel et al., 2016). AquaDiva seeks to elucidate the critical role of water fluxes connecting surface conditions with biogeochemical functions in the subsurface. One of the goals of this project is to understand how far signals of surface properties, like land cover or land management, can be traced into the subsurface water and solute dynamics. Spatially explicit travel-time distributions are the appropriate analytical tool to investigate such questions.

By virtue of using the modeled data from mHM, we are able to address several questions that have not been investigated before. First, how are spatially distributed quantities, in particular land cover, precipitation and soil type, impacting travel-time behavior in the soil? Unlike earlier model-based studies, $\mathrm{mHM}$ is a spatially distributed hydrological model. We can therefore improve the current knowledge by investigating the travel-time behavior for every $\mathrm{mHM}$ grid cell and relate it to its geophysical and climatic properties. Next, how do different hydrological regimes (wet vs. dry) impact traveltime behavior in the soil? Here, we investigate the impact of changing external conditions (meteorological factors) using the long time series of modeled fluxes and states. Finally, what is the inter-connection between travel-time behavior and specific conceptualization of different hydrological processes, and how may these connections be used for further improvement of model parameterization? Investigating the impact of model-specific conceptualizations on the predicted travel-time behavior can provide a better understanding of how actual measurement may be connected to certain model parameters. For the quantitative analysis, we focus on soil moisture only; i.e., we exclude groundwater. This is necessary due to the implementation of groundwater in mHM as a linear reservoir. Although variations, i.e., fluxes, of the groundwater level can be represented well (Rakovec et al., 2016), the total storage remains uncertain. This is a common feature of hydrological models (Fan, 2015) and mHM is no exception. Furthermore, we consider this restriction to be acceptable within the scope of our study, i.e., elucidation of the spatio-temporal dynamics of TTDs. Groundwater by definition is far less impacted by the spatial distribution of precipitation or land cover. In addition, Benettin et al. (2015b) recently showed that TTDs show little temporal variability compared to soil moisture.

To present our results on the above questions, the rest of the paper is organized as follows: in Sect. 2 we describe the numerical and analytical tools used in this study. This comprises the framework of travel-time distributions as applied in this study as well as the relevant features of mHM. In Sect. 3, we present the results of our study and demonstrate how they relate to the questions raised above. Finally in Sect. 4, we summarize our main findings in light of these questions and draw some conclusions.

\section{Methods}

In the following, we provide a short overview of the analytical and numerical tools and methods used in this study. We start by introducing the concept of travel-time distributions. To that end, we use the nomenclature as given by Benettin et al. (2015a) and the theoretical framework by Botter 
et al. (2010). Then, we give a short overview of the numerical model (mHM) which was used for the calculation of the states and fluxes. Finally, we introduce the catchment used in our study.

\subsection{Travel-time distributions for a single control volume}

Travel-time distributions are a stochastic description of the dynamic of a water parcel moving through a given CV. The definition of such a control volume for a real-world situation is often arbitrary to some extent (see, e.g., the schematic in Fig. 1). Within the context of this study, we used a spatially distributed model where the catchment is partitioned in regular grid cells (for more details, see Sect. 2.2 below). Consequently, the boundaries of our $\mathrm{CV}$ were given by the grid cells of the model.

Given that such a CV can be defined, it is clear that the dynamics of a water parcel are determined by the influxes and outfluxes that are changing the water content or storage. The time evolution of this storage $S$ inside such a $\mathrm{CV}$ is then given by the following balance equation:

$$
\frac{\mathrm{d}}{\mathrm{d} t} S(t)=Q_{\text {in }}(t)-Q_{\text {out }}(t)=J(t)-(\mathrm{ET}(t)+Q(t)) .
$$

Equation (1) is a simple initial-value problem with the influx $Q_{\text {in }}(t)$ given by the effective precipitation $J(t)$, whereas the outflux $Q_{\text {out }}(t)$ is given by evapotranspiration $\operatorname{ET}(t)$ and runoff per grid cell $Q(t)$.

To denote the different times involved in the dynamic of a water parcel, we followed the notation of Benettin et al. (2015a). Chronological time was accordingly denoted with $t$, whereas the water parcel entered the $\mathrm{CV}$ at $t_{\text {in }}$ and left at $t_{\mathrm{ex}}$. At any given time $t^{\prime}$ between these two points, a water parcel can therefore be characterized by two different properties: its age $T_{\mathrm{A}}$ as well as its (remaining) life expectancy $T_{\mathrm{E}}$ (see Fig. 2).

In their paper, Benettin et al. (2015a) emphasize the two interpretations that originate from these two points of view. Age is a backwards concept referring to the time passed since the beginning. The associated travel-time distribution is therefore called the backward TTD. The concept of backward TTDs is of particular interest for the characterization of, e.g., a water sample, since its composition is determined by the age of the water in the CV. Life expectancy, on the other hand, is a forward concept since it is referring to the time still left until exit from the CV. The associated travel-time distribution is therefore called the forward TTD. Such forward TTDs are relevant, e.g., for tracer tests, since the concentration of an ideal tracer at the outlet is given by the TTD of its associated water parcel.

To derive the TTDs associated with the forward and backward formulations, Botter et al. (2011) presented a derivation using only the states and fluxes inside the CV as well as what they call an age function (for more information on

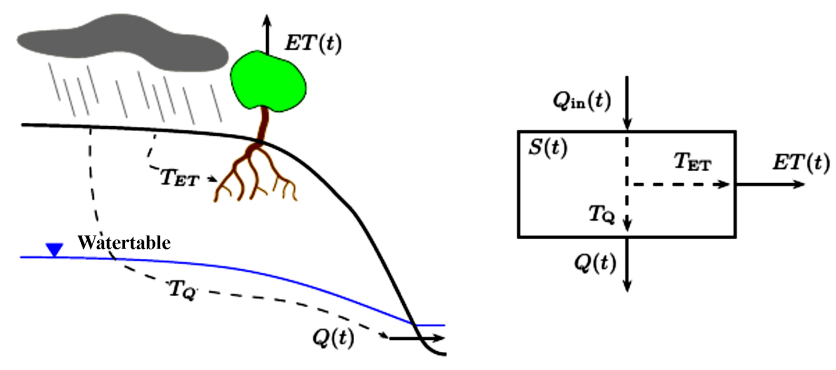

Figure 1. Water movement inside a hillslope (physical schematic on the left and conceptual schematic on the right).

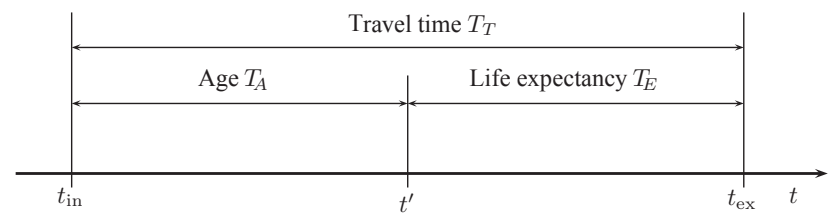

Figure 2. Schematic of different times associated with the traveltime dynamics of a water parcel. Age $T_{\mathrm{A}}$ is the time elapsed at $t^{\prime}$ since the water parcel entered the $\mathrm{CV}$ at $t_{\mathrm{in}}$, whereas life expectancy $T_{\mathrm{E}}$ is the time remaining at $t^{\prime}$ until the water parcel leaves at $t_{\mathrm{ex}}$.

their derivation, we also refer to Botter et al., 2010, and the references therein). In the following, we assume a uniform age function only. This means that the age distribution of the water leaving the $\mathrm{CV}$ is the same as the age distribution of the water inside the $\mathrm{CV}$; i.e., no age preference of the outflow generating processes (discharge and ET) exists. This decision became necessary since we could not yet draw on any data for the age distribution of water at the outlet of the catchment. As a result, we were not able to compare the predictions of different age functions to any measurements and therefore determine the most adequate description. In the absence of such data, the most appropriate choice is the one involving the least amount of information, which is given by the assumption of uniform sampling. Using this assumption, we can state the following for the forward formulation:

$$
\vec{p}_{\mathrm{Q}}\left(T_{\mathrm{E}}, t_{\text {in }}\right)=\frac{Q(t)}{\theta\left(t_{\text {in }}\right) S(t)} \exp \left(-\int_{T_{\mathrm{E}}} \frac{Q\left(t^{\prime}\right)+\mathrm{ET}\left(t^{\prime}\right)}{S\left(t^{\prime}\right)} \mathrm{d} t^{\prime}\right)
$$

with $T_{\mathrm{E}}=t-t_{\mathrm{in}}, t>t_{\mathrm{in}}$, i.e., the time from the moment the water parcel entered the reservoir until now. The function $\theta$ in Eq. (2) is called the partition function (Botter et al., 2010, 2011) and can be derived using the following formula:

$\theta\left(t_{\text {in }}\right)=\int_{t_{\text {in }}}^{\infty} \frac{Q(t)}{S(t)} \exp \left(-\int_{T_{\mathrm{E}}} \frac{Q\left(t^{\prime}\right)+\mathrm{ET}\left(t^{\prime}\right)}{S\left(t^{\prime}\right)} \mathrm{d} t^{\prime}\right) \mathrm{d} t$.

This partition function describes the portion of the water parcel, entering the $\mathrm{CV}$ at $t_{\text {in }}$, that leaves eventually as discharge 
(as opposed to leaving as evapotranspiration). It is consequently a dimensionless number between 0 and 1 .

For the backward formulation, we can state the following:

$\overleftarrow{p}_{\mathrm{Q}}\left(T_{\mathrm{A}}, t_{\mathrm{ex}}\right)=\frac{J(t)}{S(t)} \exp \left(-\int_{T_{\mathrm{A}}} \frac{Q\left(t^{\prime}\right)+\mathrm{ET}\left(t^{\prime}\right)}{S\left(t^{\prime}\right)} \mathrm{d} t^{\prime}\right)$

with $T_{\mathrm{A}}=t_{\mathrm{ex}}-t, t<t_{\mathrm{ex}}$, i.e., the time from now until the moment the water parcel leaves the reservoir.

Both these formulations determine the travel time of the water leaving as discharge. The TTDs for the water leaving as evapotranspiration can be determined in an analogous way and is not repeated here.

\subsection{Numerical model}

We used the spatially distributed, grid-based mesoscale Hydrological Model (mHM; Samaniego et al., 2010a; Kumar et al., 2013a) to generate the states and fluxes needed for the TTD analysis described above. The model uses the grid cell as a primary hydrological unit and models the following dominant hydrological process: interception, snow accumulation and melting, soil moisture dynamics, evapotranspiration, surface flow, interflows, recharge and baseflow. The total runoff generated at each grid cell is routed to the neighboring downstream cell following the river network using the Muskingum-Cunge routing algorithm. Interested readers may refer to Samaniego et al. (2010a) for further details on the model components. The model code is open source and can be downloaded from www.ufz.de/mhm. The model has been successfully applied to a number of river basins across Germany, the USA and Europe (Samaniego et al., 2010a, b, 2013; Kumar et al., 2010, 2013a, b; Livneh et al., 2015; Thober et al., 2015; Rakovec et al., 2016).

An important and unique feature of $\mathrm{mHM}$ is its multiscale parameter regionalization (MPR), which explicitly accounts for sub-grid variability of basin physical characteristics such as terrain, soil, vegetation, and geological properties (Samaniego et al., 2010a; Kumar et al., 2013a). The model considers different levels of spatial resolution to better account for spatial heterogeneity of inputs, forcings and the modeled hydrological processes (see the schematic in Fig. 3). The smallest scale (called $l_{0}$ within the mHM nomenclature) represents morphological factors like elevation, soil type and land cover. On the other hand, meteorological inputs can be represented on a larger scale (called $l_{2}$ within $\mathrm{mHM}$ ). The modeling of the hydrology is done on a third scale (called $l_{1}$ within $\mathrm{mHM}$ ) that can vary depending, e.g., on catchment size or computational resources. Based on the MPR technique, morphological inputs are linked to internal model parameters (e.g., through the use of pedo-transfer functions) and a set of regional coefficients (or global parameters $\gamma$ ). In a second step, the internal parameters are upscaled to the resolution of the hydrological processes, i.e., $l_{1}$, using parameter specific upscaling operators. Thus, MPR takes sub-grid

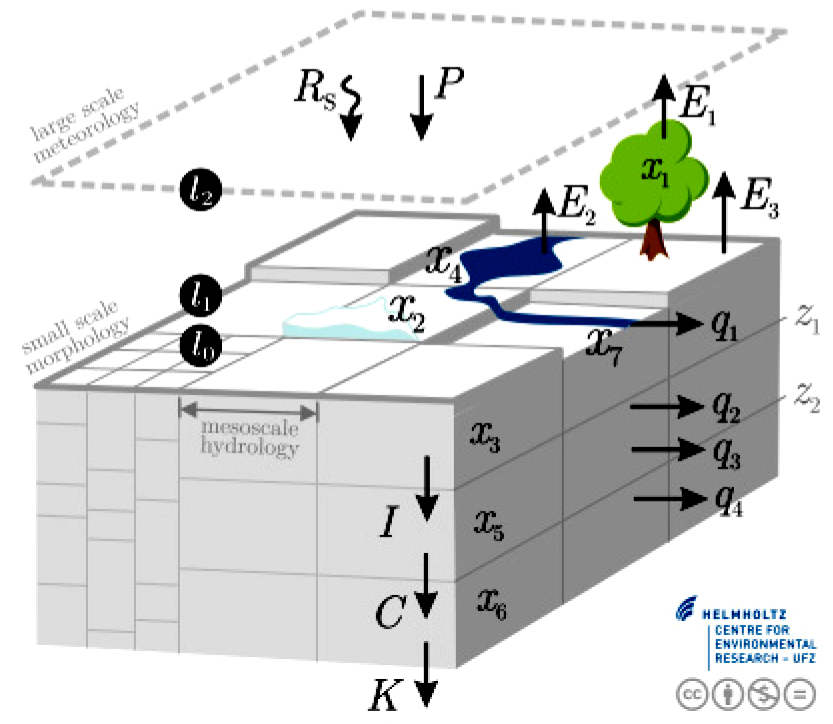

Figure 3. Schematic of the mesoscale hydrological model used in the study, depicting the different scales as well as the states and fluxes represented in a single cell.

variabilities into account indirectly. The global parameters are space- and time-invariant and are inferred via a calibration procedure. $\mathrm{mHM}$ has 66 global parameters, which is a reasonable number for an optimization problem and is therefore able to avoid overparameterization. Further details on MPR can be found in Samaniego et al. (2010a) and Kumar et al. (2013a).

Relevant to this study are near-surface and root-zone hydrological processes, which are computed using different conceptualizations. In the top layer ( $x_{3}$ in Fig. 3), water content is estimated using the infiltration excess approach similar to the HBV model (Bergström, 1995), but enhanced to account for multiple sub-layers. Within these sub-layers, the water is either percolating into deeper layers or evapotranspirating to the atmosphere. Therefore, the root zone is characterized by effective parameters for porosity, saturated hydraulic conductivity and the permanent wilting point, which are estimated based on the pedotransfer functions of Zacharias and Wessolek (2007). These effective parameters are estimated due to transfer functions from the global parameters, which are determined during the calibration process. Evapotranspiration is estimated based on potential evapotranspiration, root water uptake and water availability in layer $x_{3}$. In the second layer ( $x_{5}$ in Fig. 3), two different types of interflow take place. Slow interflow $q_{3}$ is implemented using a power-law model, whereas fast interflow $q_{2}$ is triggered when a threshold value $\gamma_{\mathrm{TV}}$ is reached, i.e.,

$q_{3}=\gamma_{s} x_{5}^{(1+\alpha)}$,

$q_{2}=\left\{\begin{array}{rl}\gamma_{f}\left(x_{5}-\gamma_{\mathrm{TV}}\right), & \text { if } x_{5}>\gamma_{\mathrm{TV}} \\ 0, & \text { otherwise }\end{array}\right.$. 
In the third level ( $x_{5}$ in Fig. 3 ) baseflow $q_{4}$ is generated using a simple reservoir model, i.e.,

$q_{4}=\gamma_{\mathrm{b}} x_{6}$.

These runoff generation processes are represented at every grid cell of mHM. The sum of direct runoff $q_{1}$ (not used for the analysis), interflows and baseflow constitutes the gridspecific total runoff which is then routed through a river network. Interested readers may refer to Samaniego et al. (2010a) or http://www.ufz.de/mhm (user manual) for further details on mHM.

As motivated in Sect. 1, we followed the concept of, e.g., Botter et al. (2010) and Benettin et al. (2015b) and divided the subsurface into two distinct zones: the soil zone (called the root zone by Botter et al., 2010, and shallow storage by Benettin et al., 2015b) and the saturated zone (called groundwater region by Botter et al., 2010 and deep storage by Benettin et al., 2015b). All analysis in our study was performed with respect to the former. This was seen as necessary due to the large uncertainties associated with storage estimation of the deeper regions. Whereas $\mathrm{mHM}$ has been demonstrated to provide good estimates for soil moisture (Rakovec et al., 2016), storage estimates for groundwater ( $x_{6}$ in Fig. 3) are far less reliable. Focusing on the soil zone only was seen as justified since the focus of our study was the investigation of spatially distributed factors like precipitation, land cover and soil type, which have comparably little impact on groundwater dynamics. Furthermore, Benettin et al. (2015b) recently demonstrated that travel-time behavior in the deeper zone has comparably little temporal variability, too.

For computation of the TTDs according to Eqs. (2) through (4), we used the combined estimates of layer $x_{3}$ and $x_{5}$ of mHM for the storage $S$ (see Figs. 3 and 4). For ET, we used the evapotranspiration fluxes from the sub-layers of $x_{3}$ and for $Q$ we used $q_{2}, q_{3}$ and $C$. Conceptually, the interflow is generated in the unsaturated zone (reservoirs $x_{3}$ and $x_{5}$ ) within mHM. Thus, using the interflow as the outflow from the unsaturated zone for deriving the travel times is a valid assumption. Our delineation of shallow and deeper storage was therefore more similar to Benettin et al. (2015b) than to Botter et al. (2010).

\subsection{Study area and model setup}

In this study, we used a mesoscale catchment in central Germany with a drainage area of approximately $1000 \mathrm{~km}^{2}$ to the gauging station at Nägelstedt (see Fig. 5). The catchment comprises the headwaters of the Unstrut River basin and was selected in this study for its relevance to Collaborative Research Center AquaDiva (Küsel et al., 2016). The terrain elevation within the catchment ranges between 170 and $520 \mathrm{~m}$, with the higher regions in the west and south being the forested hill chain of the Hainich (see Fig. 5). The forested area covers approximately $17 \%$ of the catchment, while $78 \%$ of the area is covered by crop/grassland. The remaining $5 \%$

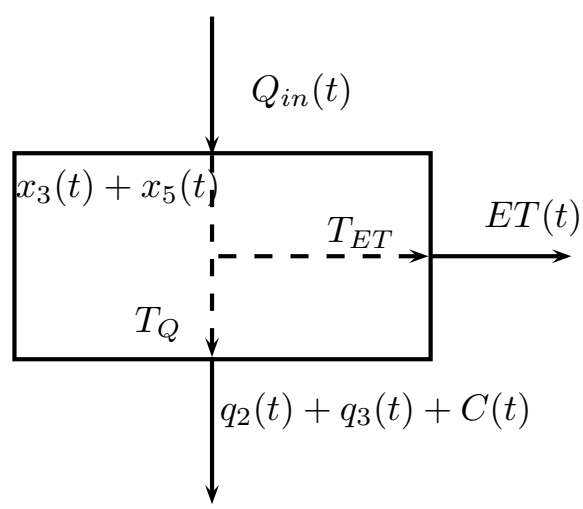

Figure 4. States and fluxes as computed by mHM (see Fig. 3) for the derivation of TTDs using Eqs. (2)-(3) (see Fig. 1).

is urban built-up area. The area is characterized by continental climatic conditions with a mean annual precipitation of approximately $660 \mathrm{~mm}$ and a mean temperature of approximately $8^{\circ} \mathrm{C}$.

We established mHM over the study catchment and performed numerical simulations on several resolutions ranging from $200 \mathrm{~m}$ to $2 \mathrm{~km}$. The model was forced using daily gridded fields of precipitation, air temperature and potential evapotranspiration. The point data sets for the precipitation and air temperature at several rain gauges and weather stations located in and around the catchment were acquired from the German Meteorological Service (DWD). These point stations were then interpolated on regular grids using an external drift kriging interpolation procedure wherein the terrain elevation was used as an external drift (Samaniego et al., 2013). The potential evapotranspiration was estimated using the Hargreaves and Samani (1985) method. Other data sets required to set up the model include a digital elevation model (DEM) and derived terrain properties like slope, aspect, flow direction and catchment boundary; soil and geological maps provided by the Federal Institute for Geosciences and Natural Resources (BGR) and metadata such as sand and clay contents, bulk density, horizon depths and dominant hydrogeological classes; CORINE land-cover information for the years 1990, 2000 and 2005 available from the European Environment Agency (EEA); and runoff data for the catchment outlet provided by the European Water Agency (EWA) and the Global Runoff Data Centre (GRDC).

The model simulations were performed for the period 1950-2005. The first 5 years of the data were used to warm up the model to acquire plausible initial conditions. We therefore discarded the first 5 years of simulations and the further analyses were performed using model outputs for the period 1955-2005. The model showed quite good performance, with NSE $>0.8$ for the daily discharge simulations at the Nägelstedt station. Other statistics such as bias and correlations were also within a satisfactory range. To further validate our model prediction, we used measurements from a single 


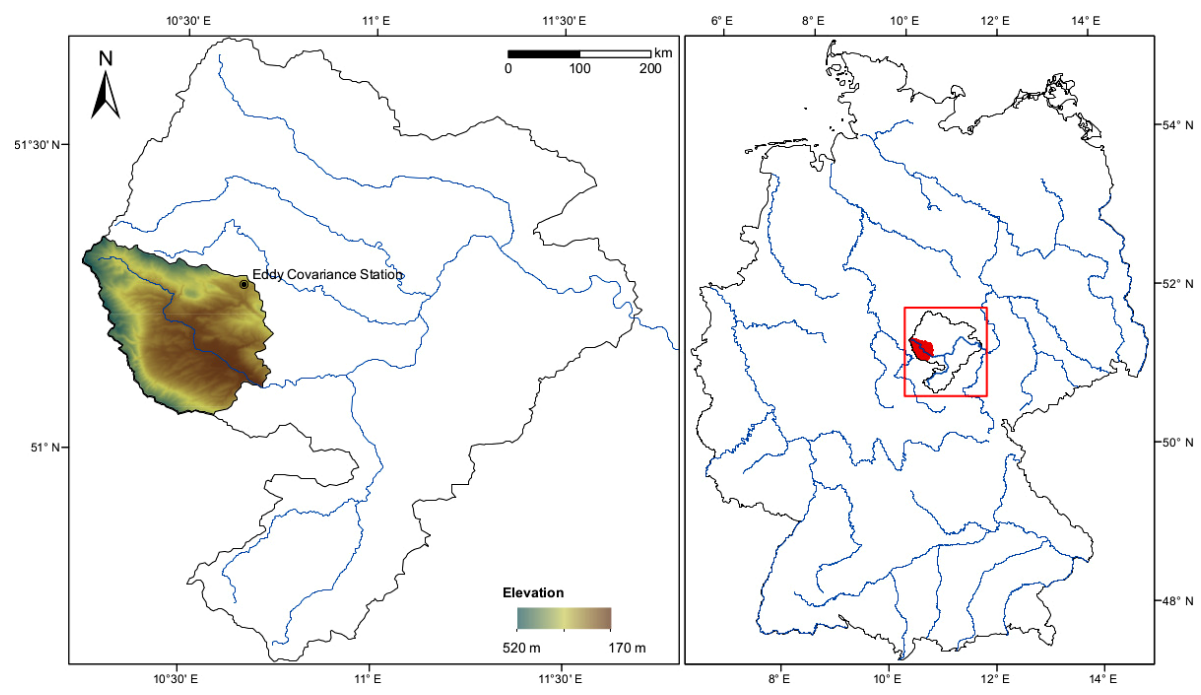

Figure 5. Left panel: catchment (highlighted) used in the study shown within the larger confines of the Unstrut catchment (area enclosed by continuous line). The larger rivers of the catchment are shown in blue. The color bar shows the elevation (in meters) of the study catchment. Right panel: Unstrut catchment within the larger confines of Germany. The axis descriptions denote the latitude and longitude values.

eddy-covariance measurement station inside the study area (see Fig. 5). This comparison also showed a good agreement between measurements and model prediction (see Fig. 6).

\section{Results and discussion}

In this section, we present and discuss the results which have been derived using the methods described above. We will begin in the following by demonstrating and exemplifying our general research procedure by virtue of a single yet representative example.

Using the time series of soil moisture, evapotranspiration, interflow and recharge, as computed by mHM, we computed the travel-time distributions for every grid cell of the catchment (see Eq. 2 and Fig. 7a). One of the problems when computing forward TTDs by virtue of Eq. (2) is that all the water entering the $\mathrm{CV}$ at time $t_{\text {in }}$ must leave by the end of the available time series. This means that a certain amount of water at the end of these time series could not be used for the analysis. To determine this period, we computed $\theta_{\text {in }}$ with respect to discharge as well as to evapotranspiration. Adding up both values for a given $t_{\text {in }}$ should add up to 1; i.e., all water that entered at $t_{\text {in }}$ should leave within the available time frame. A value smaller than 1 therefore indicates that some amount of the water is still inside the $\mathrm{CV}$ with possible error-inducing effects on the calculation of the TTDs. Analyzing this behavior, we concluded that close to 2 years at the end of the available time series had to be excluded for the calculations of the TTDs (data not shown). The shape of the resulting time-dependent distributions varied strongly, depending particularly on rainfall events that triggered the mobilization of older water stored within the soil. Another factor, although

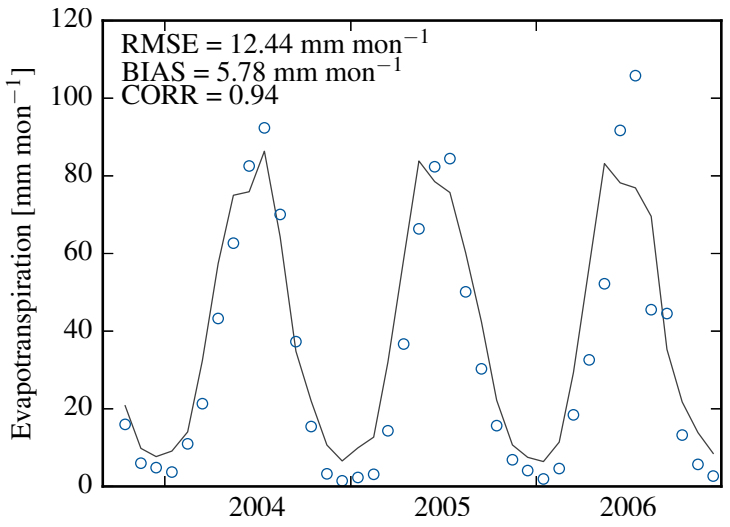

Figure 6. Comparison between monthly measured and modeled evapotranspiration (ET) at eddy-covariance station Mehrsted (see Fig. 5).

not apparent from Fig. 7, was the water content, i.e., the state of the soil itself. As has been demonstrated by Niemi (1977), soil response to rain events is strongly different between wet or dry conditions.

To disentangle these event-driven as well as statedependent effects from other factors that influence the water movement in the soil, we averaged these time-dependent distributions. As a result, we got the stationary TTDs for every cell:

$\vec{p}_{\mathrm{Q}}\left(T_{\mathrm{E}}\right)=\int \frac{Q(t)}{\theta\left(t_{\mathrm{in}}\right) S(t)} \exp \left(-\int_{T_{\mathrm{E}}} \frac{Q\left(t^{\prime}\right)+\mathrm{ET}\left(t^{\prime}\right)}{S\left(t^{\prime}\right)} \mathrm{d} t^{\prime}\right) \mathrm{d} t_{\mathrm{in}}$,

with $T_{\mathrm{E}}=t-t_{\mathrm{in}}, t>t_{\mathrm{in}}$. 


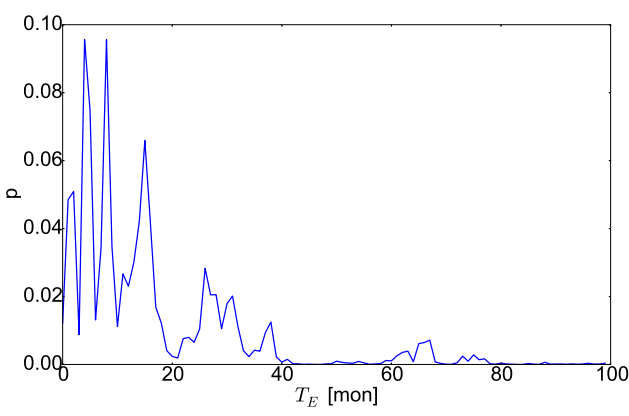

(a) Time-dependent TTD

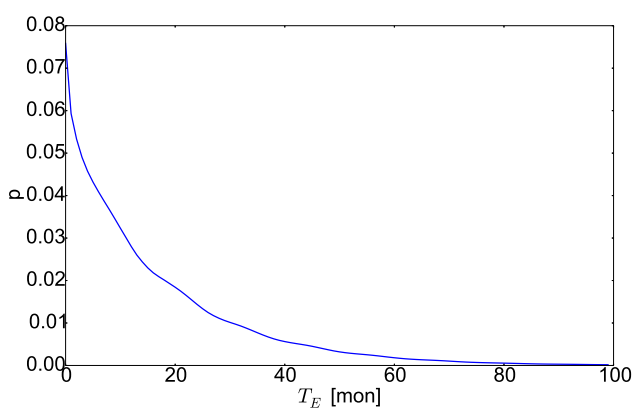

(b) Stationary TTD

Figure 7. Forward TTD of soil moisture with respect to mean travel time (in months) for a single cell in the Nägelstedt catchment. (a) shows the time-dependent TTD derived using Eq. (2) for a given $t_{\text {in }}$. (b) shows the stationary TTD derived using Eq. (7).

In all investigated cases, these stationary TTDs could be well approximated by an exponential-esque behavior (see Fig. 7b). Such behavior is often assumed to be valid for TTDs in general such that they are consequently modeled using exponential or gamma distributions (Małloszewski and Zuber, 1982). Recent works, however, have questioned this generalization by emphasizing the time-dependent nature of TTDs (Duffy, 2010; Botter et al., 2011). The examples given in Fig. 7 exemplify these concerns by illustrating their respective origins. Consequently, we acknowledged the inherent differences between these two TTDs. Furthermore, the study area falls within a humid region, with soils being generally wet and rainfall being evenly distributed throughout the year. Under these conditions the assumption of (quasi) stationary TTDs is reasonable (Tetzlaff et al., 2007; Hrachowitz et al., 2009). These stationary TTDs provided the basis for all following analysis since they allow the description of the average hydrological response of the catchment. In addition, we also focused on travel-time behavior under specific hydrological regimes, i.e., wet and dry conditions, providing a more detailed understanding of the catchment.

For our statistical analysis, we used these stationary TTDs, which, due to their exponential-esque behavior, can be characterized by their expected value $\tau$. We call this value mean life expectancy (or mean age in the case of backward TTDs) hereafter. Estimating this value for every $\mathrm{mHM}$ cell provided therefore a single measure for the travel-time behavior in the soil without the otherwise dominating impact of single precipitation events (see Fig. 8). One feature that became immediately apparent was the long travel times in urban areas (see Fig. 8a). This can be explained by the fact that these areas are largely sealed, resulting in low infiltration rates and consequently low turnover rates inside the soil. To disentangle this sealing effect from the soil behavior, we discarded cells inside urban regions from our analysis (see Fig. 8b). This allowed us to investigate the interplay between soil properties and travel-time behavior apart from such artificial influences.

\subsection{Impact of modeling resolution}

Due to its multiscale parameterization, $\mathrm{mHM}$ is able to model catchment dynamics at different spatial resolutions with the same set of calibration parameters (see, e.g., Samaniego et al., 2010a, or Kumar et al., 2013a). Within the context of TTDs, this feature may be used to investigate the potential influence of age-dependent outflow generation. The mathematical theory for including such age dependency has been developed independently by different groups and recently been unified using the umbrella term of StorAge Selection (SAS) functions (Rinaldo et al., 2015; Harman, 2015). These functions fully describe the sampling behavior of the catchment with respect to the age distribution of the stored water when discharge is generated. Discharge from a catchment may, e.g., be primarily composed of younger or older water or it may show no preference to age whatsoever. SAS functions are therefore a concise mathematical representation of this behavior.

On a physical basis, such preference for a different water age should be interpreted as the result of complex mixing processes taking place in the subsurface of the catchment (Botter, 2012; Benettin et al., 2013; van der Velde et al., 2012). To determine the appropriate SAS function for a given catchment, predictions using different functions would have to be compared with measurements. Alternatively, the form of the SAS function can be determined by using a physically based catchment model (Cornaton and Perrochet, 2006a, b). As already mentioned above, we could not directly infer which form of a SAS function would be the most appropriate choice for our catchment. Instead, we calculated the mean life expectancy for our catchment on different scales using the uniform SAS function. We motivated this choice by the principle of least information (or principle of maximum entropy) stating that, among different alternatives, the one with the least amount of information should be chosen. Without any additional constraints, a uniform distribution is usually associated with maximum ignorance, thereby motivating the use of the uniform SAS function. 


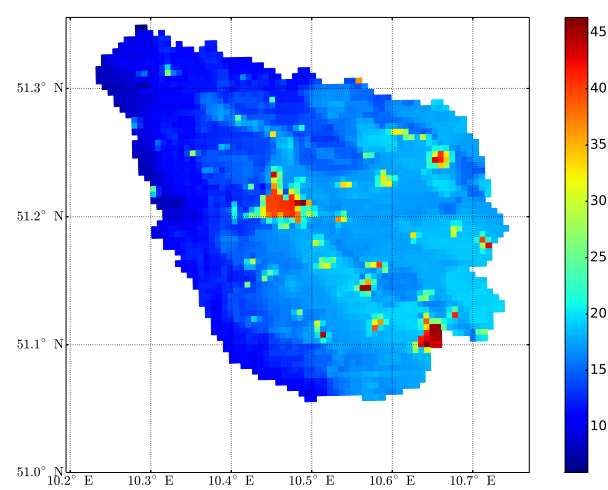

(a) All mHM-cells

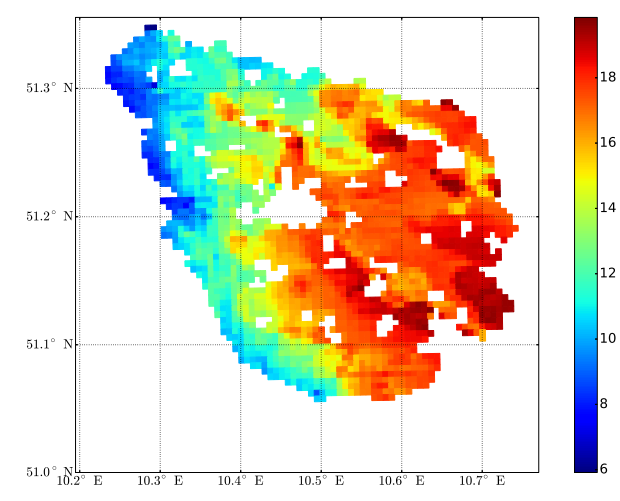

(b) Non-urban mHM-cells

Figure 8. Mean life expectancy (in months) of soil moisture derived by Eq. (7) for the Nägelstedt catchment (see also Fig. 1 for comparison) once for all mHM cells (left panel) and for all non-urban cells.

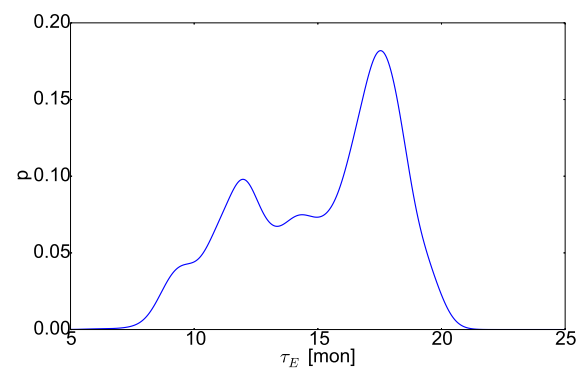

(a) $200 \mathrm{~m}$

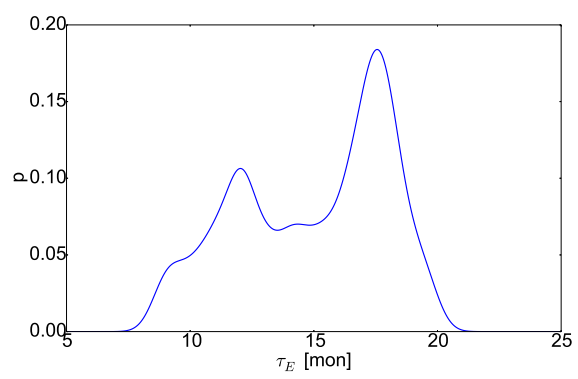

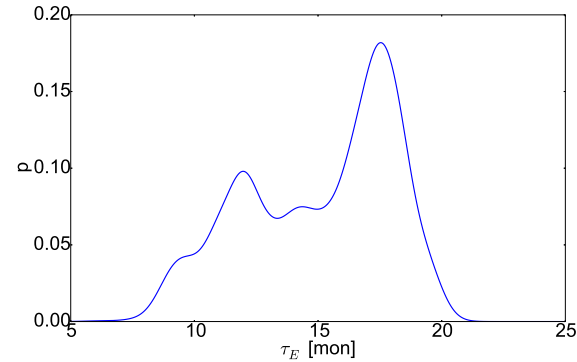

(b) $500 \mathrm{~m}$

(c) $2000 \mathrm{~m}$

Figure 9. Kernel density estimate of the mean life expectancy (in months) of soil moisture for several grid sizes in the Nägelstedt catchment.

To estimate the possible influence of this decision, we reasoned that a scale-dependent bias in the estimation of travel-time behavior would indicate the existence and possible strength of such an error. This is due to the multiscale nature of mHM, where sub-grid heterogeneity is taken into account by virtue of the multiscale parameter regionalization. Using a smaller grid size would make this heterogeneity explicit and therefore reveal any possible unaccounted subgrid influence. Results from our simulations showed no discernible differences in the statistical distribution of mean life expectancy (see Fig. 9). Using a higher resolution had a positive effect on the statistical estimation procedure due to the increase in data points. In addition, we saw more extreme values due to small-scale features that were smeared out on coarser resolutions. Other than these two changes, we noted only minor changes in the statistics of mean life expectancy. We therefore concluded that, within the limits of the spatial scales tested here, mixing processes inside our catchment had no major impact on mean life expectancy. We are aware that this assessment only covers one possible source of agedependent outflow behavior and that other unresolved heterogeneity (at even smaller scales or due to other subsurface properties not accounted for in $\mathrm{mHM}$ ) would influence the outflow generation as well. We therefore regard our conclusions as tentative and open to revision once actual measurements become available. 


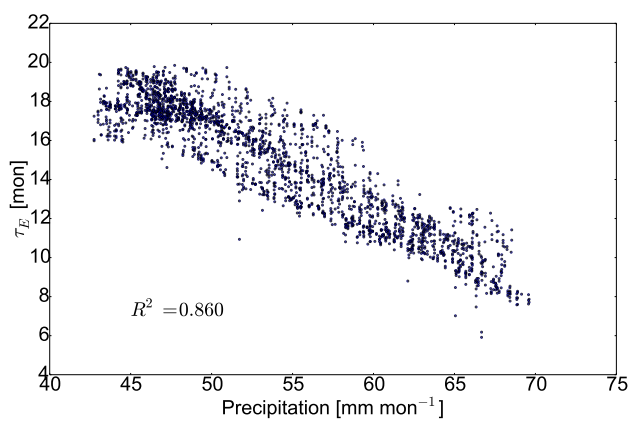

(a)

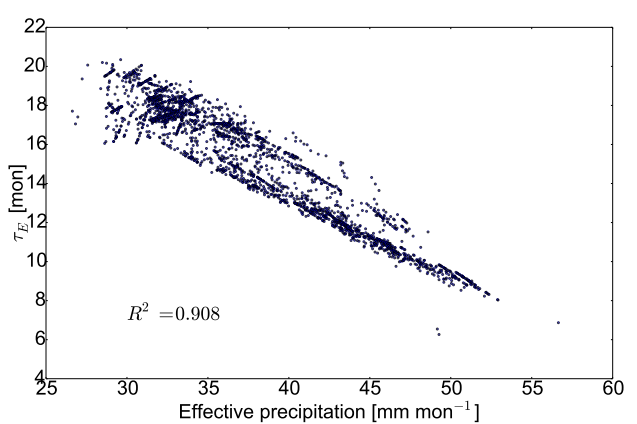

(b)

Figure 10. Scatter plot of mean life expectancy (in months) of soil moisture vs. monthly values (in millimeters) for precipitation (a) and effective precipitation (b).

However, our investigation gave us the ability to find a good trade-off between computational costs and data amount for the following statistical analyses. We therefore used a data set from simulations using a grid size of $500 \mathrm{~m}$.

\subsection{Statistical analysis of mean life expectancy}

The mean life expectancy $\tau$ of a water parcel inside a catchment is the result of a complex interplay of morphological and climatological factors. Several recent studies have therefore tried to determine their relative importance under varying conditions (McGuire et al., 2005; Cardenas, 2007; Broxton et al., 2009; Tetzlaff et al., 2009, 2011). Contrary to these studies where field measurements were used, we used results from computational simulations only. This gave us a much larger data set, both in time and space, from which we could infer the relative impact of different factors, in particular meteorological (precipitation), land surface (land cover, leaf-area index) and subsurface (soil) properties. Notably, our approach differs from Hrachowitz et al. (2009) such that our analysis is based on model-derived gridded simulations of TTDs as compared to the observation-based basin-wise quantification of TTDs.

In the first step, we determined for every cell the statistical relationship between the mean life expectancy $\tau$ and a number of potential predictors like average precipitation, soil depth, soil type or leaf-area index (LAI). Similar to Hrachowitz et al. (2009), we used the coefficient of determination $R^{2}$ to quantify the strength of the statistical relationship. This quantity equals 1 minus the ratio of the remaining variance vs. the total variance of the data themselves. It is therefore a measure of the variance explained by the statistical model (which was always assumed to be linear in our study).

\subsubsection{Precipitation}

The analysis above showed the strong impact of precipitation on the event-based TTDs (see Fig. 7). We therefore expected this quantity to exert strong controls on the steady-state TTDs as well. In our model, two different quantities can be dis- tinguished: first, the precipitation itself as well as, second, the effective precipitation. The latter value is here defined as the water flux that is actually entering the soil, i.e., corrected by surface runoff (through sealing), canopy interception and snowmelt. While the precipitation can be measured with high accuracy, it is the effective precipitation that directly impacts soil-moisture dynamics.

The scatter plots of both data sets vs. the mean life expectancy show a significant negative correlation between them (see Fig. 10). This negative relationship can be explained such that precipitation events apply pressure to the water already stored in the soil. Instead of immediately traveling through the soil, the water from these events rather pushes older water out. Strong precipitation events therefore lead to a "flushing out" of the soil and cause a shorter life expectancy.

\subsubsection{Terrain elevation}

In our next analysis, we used the physical elevation as a variable for our regression model. The height can simply be derived from the digital elevation model (DEM), which, in $\mathrm{mHM}$, is represented using data obtained from the Shuttle Radar Topography Mission.

Using a scatter plot for visualizing the statistical relationship between mean life expectancy and the DEM showed a negative correlation (see Fig. 11), i.e., longer life expectancy correlated with lower heights of the terrain, and with a linear coefficient of determination of $R^{2}=0.668$. Since no direct causal connection can be drawn between physical elevation and travel-time behavior, such a high value is indicative of underlying mechanisms. One of these is the aforementioned precipitation, since higher altitudes are correlated with stronger mean precipitation levels (linear coefficient of determination of $R^{2}=0.812$ ). Performing a multiple linear regression, including precipitation and saturated soil moisture (discussed below), showed strong correlation between these variables (data not shown). It therefore stands to reason to attribute potential causal effects to these covariates only. 


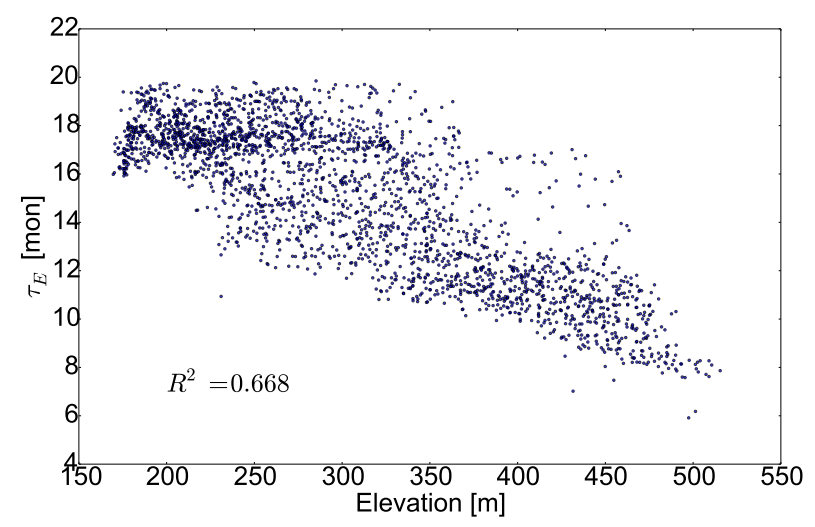

Figure 11. Scatter plot of mean life expectancy (in months) of soil moisture vs. elevation (in $\mathrm{m}$ ).

\subsubsection{Evapotranspiration}

Evapotranspiration is directly influencing the form of a TTD (see, e.g., Eq. 2). Consequently, we anticipated a strong correlation between mean evapotranspiration rates and mean life expectancy.

With respect to evapotranspiration, two different definitions are typically distinguished: potential evapotranspiration (PET) and actual evapotranspiration (AET). As implied by its name, PET describes the maximum possible rate of evapotranspiration at a given site. This value is dependent on quantities like solar radiation and temperature that can generally be measured with good accuracy (Samani, 2000). Using theoretical models, good estimates can therefore be provided for PET at a given site (Almorox et al., 2015). On the other hand, AET is a real quantity that can be measured. In principle, in situ measurements can therefore provide good estimates (e.g., the eddy-covariance method). In practice, however, exact measurements are hampered by a series of factors (Wang and Dickinson, 2012). As a consequence, PET can often be estimated with higher accuracy than AET.

Scatter plots of both PET and AET show a positive correlation between evapotranspiration and mean life expectancy in general (see Fig. 12). This correlation is more pronounced for AET, with a coefficient of determination of $R^{2}=0.496$ vs. only $R^{2}=0.259$ for PET.

In contrast to precipitation, which is an inflow mechanism, ET is an outflow mechanism. It does not push, but rather pulls the water out of the $\mathrm{CV}$, which explains the difference in behavior between precipitation and ET. The lower relative strength of the correlation (compared to precipitation) can be explained such that ET is only one of the two outflow mechanisms (the other being discharge). The relative stronger impact of AET compared to PET was also anticipated. AET is directly used in Eq. (2) for the calculation of TTDs, whereas PET is only coupled by virtue of an additional function.

As explained above, for real-world situations, better estimates can often be provided for PET. The higher explanatory power of AET has to therefore be balanced with its often less accurate estimate. Depending on the accuracy of measurements of AET, PET estimates may be a better predictor of mean life expectancy.

\subsubsection{Land-cover properties}

Land cover is an important interface controlling the strength of incoming fluxes through artificial and natural sealing. In $\mathrm{mHM}$, three different land-cover types are distinguished: forest, crop/grassland and urban area. As explained above, we excluded mHM cells inside urban areas from our analysis in order to better focus on the soil properties themselves. To further elucidate possible influence of the remaining land-cover types, we separated the catchment into forest and crop/grassland and calculated the mean travel times separately.

Estimating the probability density function (PDF) of the mean life expectancy for both land-cover types separately revealed strong differences between them both in shape of the respective PDF and the range of values (see Fig. 13). As shown above, results for the combined data set showed a distinct bimodal behavior (see Fig. 9). In contrast to that, the PDFs for both land-cover types were almost unimodal. The most dominant peaks of every single PDF coincided with the two peaks of the combined PDF. The behavior of the latter can therefore - to some degree - be considered to be a superposition of the former.

The relationship between these two land-cover types was such that forest resulted in much shorter mean travel times compared to crop/grassland. This pronounced difference may be partially due to a correlation with precipitation values that have already been shown to exert a strong influence on travel-time behavior. Forest in the study catchment (as well as in Germany in general) is found disproportionately in hilly and mountainous regions. These regions in turn show stronger precipitation values. The tendency depicted in Fig. 13 may therefore be caused by this covariate. However, this correlation between forested and high-precipitation area would not explain the distinct differences between both land-cover types. Another factor, overlapping with the former, may be due to the differences in water uptake. Trees are rooted into deeper soil layers compared to crop and grass and are therefore able to access a larger part of the subsurface water body. This larger access combined with the higher precipitation values as well as other factors would explain the almost non-overlapping travel-time behavior demonstrated in Fig. 13.

In addition to this classification scheme, $\mathrm{mHM}$ uses the leaf-area index (LAI) to describe land-cover properties. The LAI describes the ratio of the cell that is effectively covered by plant canopy. Due to the already established influence on evapotranspiration (see above), it stands to reason that an influence on the mean life expectancy exists as well. Comparing LAI class and land cover reveals a strong overlap between 


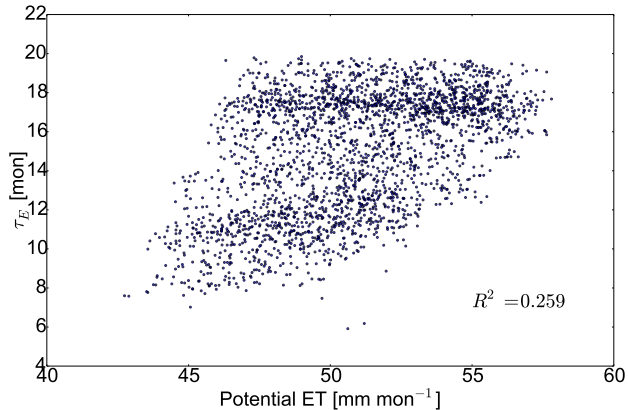

(a)

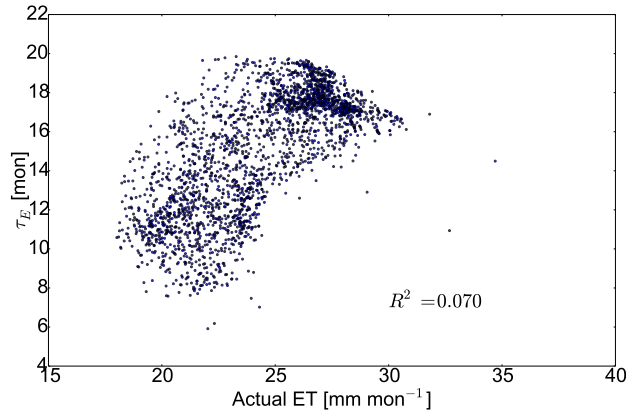

(b)

Figure 12. Scatter plot of mean life expectancy (in months) of soil moisture vs. monthly evapotranspiration values (in millimeters). Displayed are both potential evapotranspiration (a) and actual evapotranspiration (b).

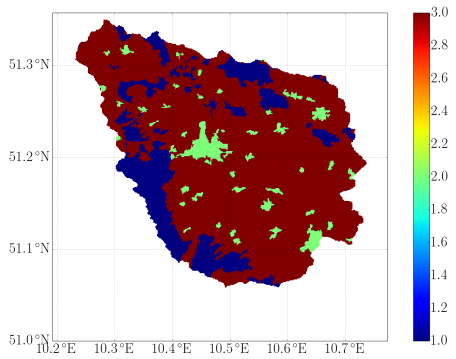

(a) Spatial distribution

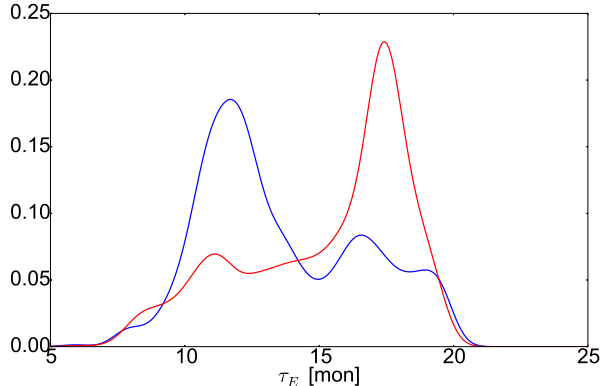

(b) Kernel density estimate

Figure 13. Land cover in the Nägelstedt catchment (blue: forest; green: urban; red: crop/grassland). (a) shows the spatial distribution of land cover in the highest resolution $l_{0}$ and (b) shows the kernel density estimates of the mean life expectancy (in months) of soil moisture for the land-cover types.

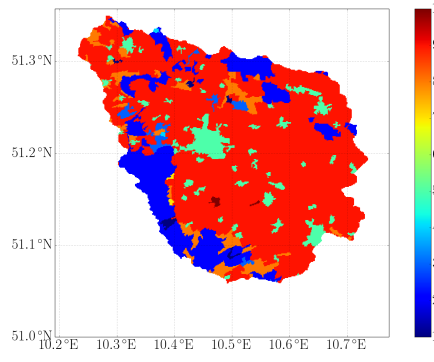

(a) Spatial distribution

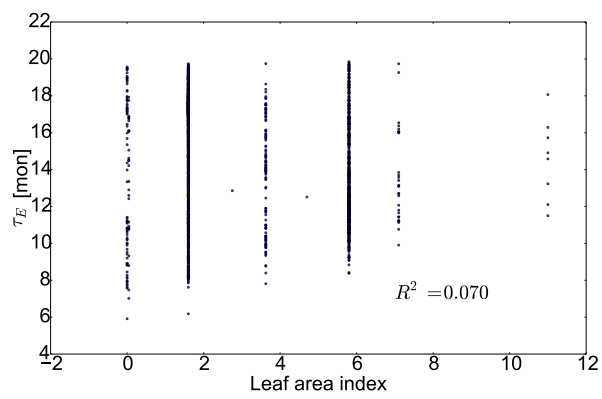

(b) Scatter plot

Figure 14. Leaf-area index (LAI) in the Nägelstedt catchment. (a) shows the spatial distribution and (b) shows the scatter plot of mean life expectancy (in months) of soil moisture vs. LAI.

both (see Figs. 13a and 14a). Roughly, forest corresponds to LAI classes 1-4, urban area corresponds to LAI class 5 and grassland corresponds to LAI classes 6-10.

Using the same approach as above, i.e., investigating the mean life expectancy for every LAI class independently, revealed the same overall tendency for LAI classes compared to land-cover types (data not shown). This was anticipated due to the aforementioned overlap between the two classifi- cation schemes. In addition, we saw little diversity for LAI classes within the same land-cover class (data not shown).

However, this tendency was not present when using the actual leaf-area values associated with every LAI class. These values could be constant over the year (e.g., in the case of coniferous forest) or vary strongly (e.g., in the case of deciduous forest). To make values from different LAI classes comparable, we averaged the respective values year-wise. A scatter plot of leaf-area index vs. mean life expectancy does 


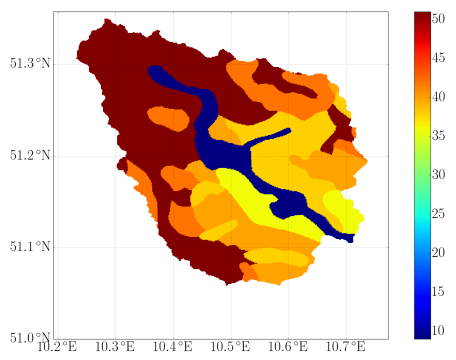

(a) Spatial distribution

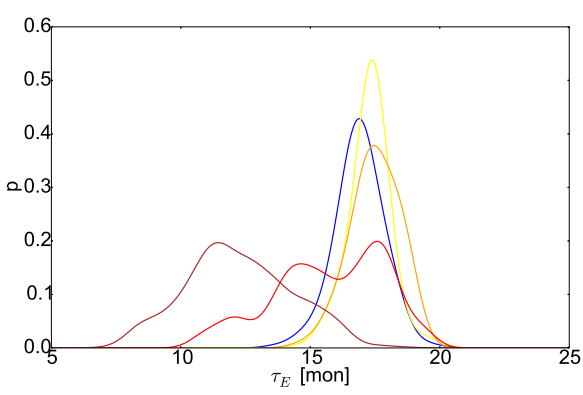

(b) Kernel density estimate

Figure 15. Soil classes in the Nägelstedt catchment. (a) shows the spatial distribution and (b) shows the kernel density estimate of the mean life expectancy (in months) of soil moisture for selected soil classes. The blue curve represents soil class 9 (36\% sand and $10 \%$ clay), the yellow curve represents soil class 38 (12\% sand and $15 \%$ clay), the orange curve represents soil class 40 ( $10 \%$ sand and $19 \%$ clay), the red curve represents soil class 42 (7\% sand and 39\% clay) and the brown curve represents soil class 51 (19\% sand and $70 \%$ clay).

not show strong correlation between the two, with similar ranges of values being found for almost all LAI values (see Fig. 14b). This discrepancy can be explained by the implementation of the LAI in mHM. In contrast to the land-cover type that is used for the determination of ET processes in the top soil layer, LAI values are only used for interception and consequently do not directly influence travel-time behavior. As a result, any possible relationship between LAI and TTDs is therefore biased and conclusions from our results must take into account this limitation critically.

\subsubsection{Soil properties}

An important input parameter in $\mathrm{mHM}$ is the soil type inside every cell. This property is implemented in $\mathrm{mHM}$ using German soil database Bodenübersichtskarte 1: 1000000 (BÜK 1000) (BGR, 1998).

Due to this relevance in the model, we anticipated a strong impact of the soil type in a cell on the resulting mean life expectancy. Estimating the PDF of mean travel times for every soil type individually did indeed show significant differences between them (see Fig. 15). Soil classes found in the geographically lower regions of the catchment generally show longer mean travel times with a unimodal distribution shape, whereas soil types in the geographically higher regions correspond to generally shorter mean travel times, with the shape of the distributions being less regular. This qualitative analysis reveals some overlap with the land-cover distributions as well as mean precipitation rates. It is consequently not possible to directly infer causal correlation from statistical correlation.

In addition, the soil class is a symbolic variable; i.e., its values only indicate a certain type of soil but do not directly relate to any numerical quantity associated with this soil type. Consequently, we could not infer any quantitative connection between soil types and resulting travel-time behavior.

To address this problem, we used the saturated soil moisture of the soil. This quantity is the amount of pore space per

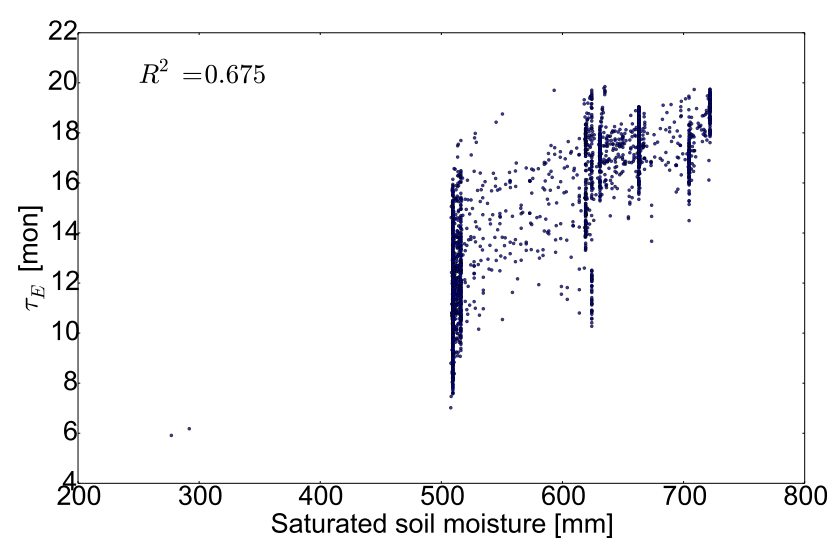

Figure 16. Scatter plot of mean life expectancy (in months) of soil moisture vs. saturated soil moisture (in millimeters).

cell that can be potentially filled with water (porosity times the depth of root-zone soil layer). Its value is determined in mHM through pedo-transfer functions using the soil textural information on percentage of sand, clay and bulk density. Comparing these values in every single cell with the mean life expectancy shows a very strong statistical relationship with a coefficient of determination $R^{2}=0.675$ (see Fig. 16).

The high correlation values of the saturated soil moisture can be explained by a mixture of causal and statistical factors. On one hand, it is reasonable to expect the total amount of storage to be filled with water to have a significant effect on the resulting travel-time behavior. On the other hand, the soil types show a strong overlap with other factors like precipitation levels and land-cover types that have already been discussed above.

\subsection{Statistical analysis of mean age}

As described above, the difference between the forward and backward formulations of travel time has long been acknowledged (Niemi, 1977) and many studies have investigated 


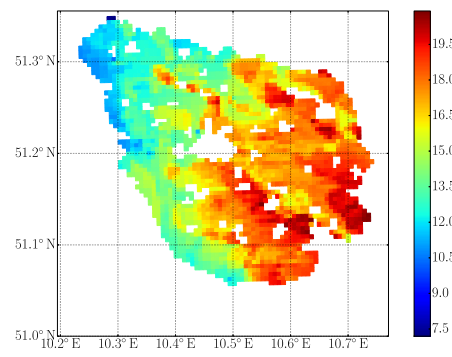

(a) Spatial distribution

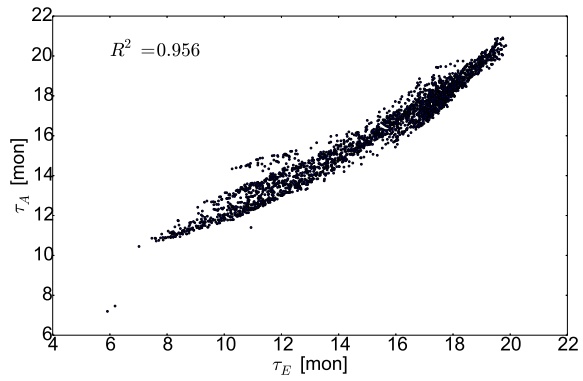

(b) Scatter plot

Figure 17. Mean age of soil moisture in the Nägelstedt catchment. (a) shows spatial distribution and (b) shows the scatter plot of mean age vs. mean life expectancy (see Eq. 8) in months.

their relationship (Cornaton and Perrochet, 2006a; Botter, 2012; Benettin et al., 2013, 2015a; Harman, 2015). Both these formulations are linked by virtue of the so-called Niemi relation

$J\left(t_{\text {in }}\right) \theta\left(t_{\text {in }}\right) \vec{p}\left(t-t_{\text {in }} \mid t_{\text {in }}\right)=Q(t) \overleftarrow{p}\left(t-t_{\text {in }} \mid t\right)$

which can be derived by considering a water parcel entering the $\mathrm{CV}$ at $t_{\text {in }}$ and leaving at $t$. Consequently, mean life expectancy and age only coincide in the case of steady-state conditions. As a result, we also investigated the behavior of mean age to elucidate connections and differences between forward and backward formulations for our catchment.

Visually comparing mean age (see Fig. 17) and mean life expectancy (see Fig. 8b) in the Nägelstedt catchment showed strong qualitative and quantitative similarities. Accordingly, we also got a very strong statistical relationship between these two quantities, with a coefficient of determination of $R^{2}=0.956$. Overall, the relationship was very linear, with mean age values falling short of mean life expectancy for both small and large values.

Due to the mathematical and physical similarities, such a strong connection was anticipated. To further investigate possible origins of their respective differences, we performed the same statistical analysis for mean age.

To that end, we considered proxy variables that have already been shown to have a considerable impact on traveltime behavior. As demonstrated by the analysis above, these were precipitation (Pre), potential evapotranspiration (PET) and saturated soil moisture (SSM) as proxies for influx, outflux and state, respectively. Results showed overall the same trend for mean age and life expectancy with respect to these predictors (see Table 1). Precipitation was the most dominant factor for both quantities, with the saturated soil moisture being a close second. This is in contrast to, e.g., Benettin et al. (2015a), who emphasized the role of the outfluxes for the time evolution of both age and life expectancy. In our analysis, we saw that proxy variables for influx and state show the strongest correlations with mean travel-time behavior. On the other hand, PET, which is a good proxy for one of the two outfluxes, showed only moderately strong correlations with
Table 1. $R^{2}$ values for several predictors of mean travel time.

\begin{tabular}{lccc}
\hline & Pre & PET & SSM \\
\hline Mean life expectancy & 0.860 & 0.260 & 0.675 \\
Mean age & 0.728 & 0.143 & 0.711 \\
\hline
\end{tabular}

said behavior. In the case of mean age, this relationship was even weaker compared to the other two (precipitation and saturated soil moisture). Since we could not provide a proxy variable for the other outflux, i.e., discharge, we excluded this quantity from our analysis.

\subsection{Joint impact of multiple variables on mean travel times}

In the analysis above, the statistical relationship between mean travel-time behavior and a number of variables was presented and discussed. This was done for every variable individually to elucidate its possible impact on mean travel times. In addition to this simple analysis, we also investigated the joint impact of several variables. Such results can be of relevance for prediction, i.e., using a set of variables to predict travel times in a given $\mathrm{CV}$.

To that end, we used the variables that had been shown to have the highest impact individually, i.e., precipitation, saturated soil moisture and potential evapotranspiration, and performed a multiple linear regression. Simple linear regression had already demonstrated that both precipitation and saturated soil moisture could explain a significant amount of the variability contained in the data set. Combining these factors could therefore improve the predictability even further. We therefore applied forward stepwise selection to generate a series of models with increasing complexity. The first single-variable model consequently used precipitation as the variable with the highest single $R^{2}$ value. Next, the doublevariable model used both precipitation and saturated soil moisture and the most complex three-variable model used 
Table 2. $R^{2}$ values for several regression models of increasing complexity.

\begin{tabular}{lccc}
\hline & Pre & Pre + SSM & Pre + SSM + PET \\
\hline $\begin{array}{l}\text { Mean life } \\
\text { expectancy }\end{array}$ & 0.860 & 0.911 & 0.913 \\
\hline
\end{tabular}

precipitation, saturated soil moisture and potential evapotranspiration jointly.

Results for the default case showed that, compared to using only one variable (precipitation), using two variables for the regression (precipitation and saturated soil moisture) improved the predictability of mean travel times (see Table 2). This was expected since both variables alone provided already high $R^{2}$ values. In addition, precipitation and saturated soil moisture only showed moderate correlation $\left(R^{2}=\right.$ 0.451 ), so adding the latter variable added new information to the prediction model. The correlation that existed between precipitation and saturated soil moisture is explained by the orographic effect; i.e., hilly regions in the catchment with typically lower values of saturated soil moisture also show higher precipitation values. In contrast, using three variables (precipitation, saturated soil moisture and potential evapotranspiration) resulted in almost negligible improvement (see Table 2). This is due to the already lower impact of PET compared to precipitation and saturated soil moisture. In addition, PET showed comparably stronger correlation with both precipitation and saturated soil moisture (data not shown), thereby adding only little new information compared to the other two variables. Such low impact of outgoing fluxes compared to precipitation has already been reported before, for the case of synthetic toy models (Daly and Porporato, 2006). Moreover, our results agree with the findings of Hrachowitz et al. (2009), who also reported similarly strong explanatory power of climatic variables like precipitation as well as soil and land surface properties.

\subsection{Impact of hydrological regime on travel-time behavior}

The analysis above revealed the strong impact of the influx (i.e., precipitation) as well as the state variable (i.e., saturated soil moisture) on the travel-time behavior in the soil. To further elucidate their impact, we investigated the soil travel-time behavior independently for different hydrological regimes during the considered period of time, i.e., from 1955 to 2005 . To that end, we partitioned the available time series into regimes based on soil moisture (state variable) and precipitation events (influx).

In the first case, we averaged the time series of mean saturated soil moisture in the whole Nägelstedt catchment for every year, i.e., 50 years in total. Next, we divided the resulting time series such that years with an average soil moisture
Table 3. $R^{2}$ values for several predictors of mean travel time (as caused by wet and dry years).

\begin{tabular}{lccc}
\hline & Pre & PET & SSM \\
\hline Wet years & 0.374 & 0.084 & 0.388 \\
Dry years & 0.781 & 0.223 & 0.834 \\
\hline
\end{tabular}

content above the 85th percentile of the time series were labeled as wet years. In contrast, years with an average soil moisture content below the 15th percentile of the time series were labels as dry years. This year-wise partitioning was seen as necessary due to the strong annual fluctuations of this variable. Finally, we performed the same analysis as describe above for both - now smaller - data sets.

Using results from dry years only (see Fig. 18) showed a similar qualitative travel-time behavior but strong quantitative contrast compared to the mean travel-time behavior discussed above (see Fig. 8). Compared to this general case, mean life expectancy was much larger in dry years. In addition, dry years exhibit a wider range of values, with the largest one (over 50 months) being almost 4 times as large as the smallest one (approximately 12 months).

Wet years, on the other hand, exhibit a very small range of values, with the smallest value (approximately 5 months) being roughly half the largest value (approximately 11 months) (see Fig. 19). Compared to the general case, where the largest value (approximately 20 months) were roughly 3 times as large as the smallest value (approximately 6 months), these two scenarios fall on either side of this spectrum. This discrepancy demonstrates again the strong impact of the state variable (soil moisture) on travel-time behavior. Another difference between the mean travel-time behavior in wet years and the general case is the unimodal distribution of the former. The analysis above revealed how the bimodal behavior strongly correlates with the different soil types and therefore reflects the strong impact on this property on the overall soilmoisture dynamics. The disappearance of this bimodal behavior is therefore reflective of how the soil becomes more homogeneous when filled up with water.

In addition, our results showed different statistical dependencies of travel-time behavior with respect to precipitation, PET and SSM (see Table 3). Dry years showed very similar correlation values compared to the general case (see Table 1). On the other hand, correlation values for wet years were remarkably smaller.

In the second case, we investigated travel-time behavior depending on extreme values of the influx, i.e., for months having large precipitation values (rainy months). To that end, we constrained our analysis to forward travel-time distributions which were triggered by heavy rain events. This means that, in analogy to the analysis above, we only used months with precipitation values above the 97 th percentile and performed again the same analysis for the reduced data set. 


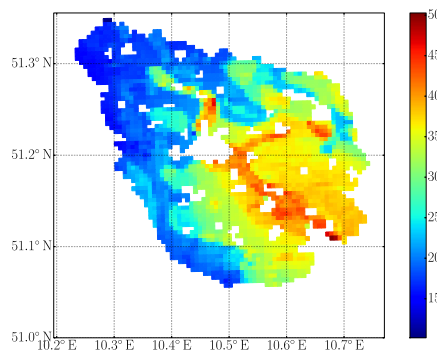

(a) Spatial distribution

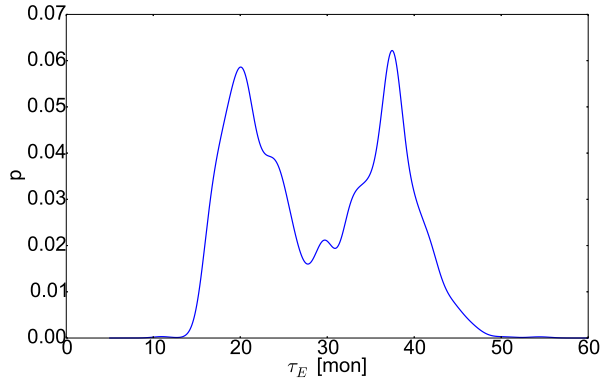

(b) Kernel density estimate

Figure 18. Mean life expectancy of soil moisture in the Nägelstedt catchment in dry years. (a) shows the spatial distribution and (b) shows the kernel density of mean life expectancy (in months).

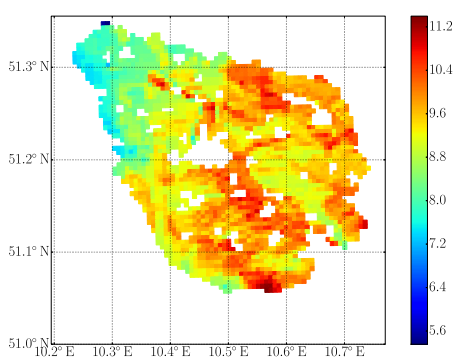

(a) Spatial distribution

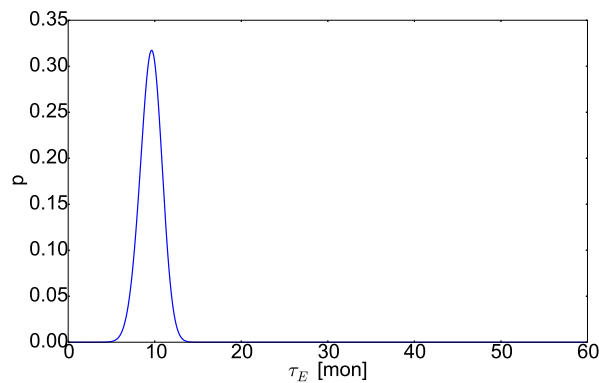

(b) Kernel density estimate

Figure 19. Mean life expectancy of soil moisture in the Nägelstedt catchment in wet years. (a) shows the spatial distribution and (b) shows the kernel density of mean life expectancy (in months).

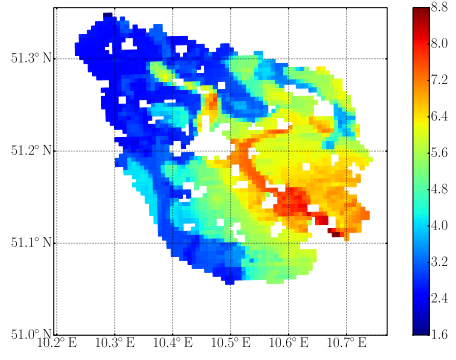

(a) Spatial distribution

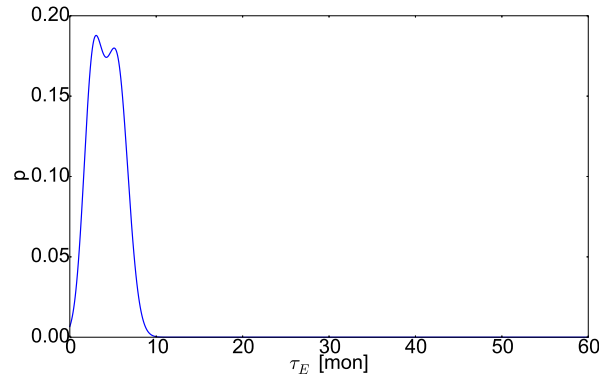

(b) Kernel density estimate

Figure 20. Mean life expectancy of soil moisture in the Nägelstedt catchment caused by rainy months. (a) shows the spatial distribution and (b) shows the kernel density of mean life expectancy (in months).

Results showed strong differences in mean life expectancy during rainy months compared to the scenarios discussed above (compare Fig. 20 with Figs. 8 and 18). Compared to wet years, we saw even lower mean life expectancy. This can be explained by the strong impact of the rain on soil moisture leading to a flushing of the soil. We also saw a similarly small variance and a nearly unimodal distribution of mean travel-time values.

In addition to that, we saw differences in the statistical correlation of mean life expectancy of precipitation, potential evapotranspiration and saturated soil moisture (see Table 4).
Table 4. $R^{2}$ values for several predictors for mean travel time (as caused by rainy months).

\begin{tabular}{cccc}
\hline & Pre & PET & SSM \\
\hline Mean life expectancy & 0.736 & 0.221 & 0.857 \\
\hline
\end{tabular}

Compared to the standard travel-time behavior, precipitation was slightly correlated with mean life expectancy. This was caused by lower overall variation in precipitation values due to constraining our analysis to large values, thereby exclud- 
ing low and medium range rain events. In contrast to that, $R^{2}$ values for PET and SSM increased.

\subsection{Relevance of TTDs for hydrological inference}

The above results demonstrated the impact of certain soil properties, as implemented in mHM, on mean travel times using the $R^{2}$ metric as a measure. In addition to that statistical analysis, their relationship can further be elucidated by analyzing Eqs. (2) or (3). Assuming for example a simple linear relationship for both $Q$ and ET with respect to $S$, we get for Eq. (2) the following:

$\vec{p}_{\mathrm{Q}}\left(T_{\mathrm{E}}, t_{\text {in }}\right)=\frac{\alpha_{\mathrm{Q}}}{\theta\left(t_{\text {in }}\right)} \exp \left(-\alpha_{\mathrm{ET}} T_{\mathrm{E}}\right) \exp \left(-\alpha_{\mathrm{Q}} T_{\mathrm{E}}\right)$.

Equation (9) shows how under such simplified assumptions, the TTD of such a CV would follow an exponential distribution with its mean travel time being related to the recession constants $\alpha_{\mathrm{Q}}$ and $\alpha_{\mathrm{ET}}$. As shown above, such an exponential behavior is visible in the mean behavior (see Fig. 7 right), whereas non-stationary TTDs show this exponential behavior to be dominated by the event-based nature of the governing fluxes (see Fig. 7 left).

In addition to these differences, we also saw different mean travel-time behavior for different regimes (see above). These differences can be explained by the actual implementation of $Q$ and ET in $\mathrm{mHM}$, which is generally nonlinear (see Sect. 2.2). To assess the different roles of each soil process in discharge generation, we calculated the relative contribution of each outflow mechanism for each regime. The data in Table 5 show how much of the water that entered the soil during a given time and left eventually as discharge was leaving as baseflow $Q_{\mathrm{B}}$, slow interflow $Q_{\mathrm{I}_{\mathrm{s}}}$ or fast interflow $Q_{\mathrm{I}_{\mathrm{f}}}$. On average, baseflow contributed the most to discharge, with fast interflow having the smallest share. This overall distribution became more strongly pronounced during dry years, with baseflow taking the largest share of outflow generation and fast interflow becoming negligible. For wet years this trend is reversed, with water entering the soil during rainy months having an almost equal distribution. These different weighs show the relative impact and therefore the relative information content that travel-time distributions could contain; i.e., travel times in dry years are mostly the results of the successive processes contributing eventually to baseflow (see Fig. 3), whereas travel times during storm events contain information on all discharge processes equally.

To further elucidate the relationship between the resulting mean travel times and certain model parameters, we performed a regression analysis comparing the recession constant for recharge with the mean travel times for different regimes. Results confirmed the relationship described above, with mean travel times during dry years showing the strongest correlation (see Table 6).

Such a high interdependency between certain model parameters and data from different flow regimes is not unique
Table 5. Relative contribution of the different fluxes to runoff generation.

\begin{tabular}{cccc}
\hline & All years & Dry years & Wet years \\
\hline$Q_{\mathrm{I}_{\mathrm{f}}}$ & 0.150 & 0.061 & 0.173 \\
$Q_{\mathrm{I}_{\mathrm{S}}}$ & 0.298 & 0.239 & 0.317 \\
$Q_{\mathrm{B}}$ & 0.552 & 0.700 & 0.512 \\
\hline
\end{tabular}

Table 6. $R^{2}$ values for recharge vs. mean travel times for different regimes.

\begin{tabular}{cccc}
\hline & All years & Dry years & Wet years \\
\hline$R^{2}$ & 0.6059 & 0.6954 & 0.3619 \\
\hline
\end{tabular}

for TTDs. Using discharge alone would reveal similar overall tendencies; e.g., discharge data from droughts are more informative for calibrating baseflow recession constants. What is new, however, is the additional information content, which is not contained in discharge data alone. Not only can this improve calibration efforts, it allows the inference of additional system states. This is particularly relevant with respect to, but not confined to, the total amount of stored groundwater. Discharge data are not sensitive to, and therefore not informative for, groundwater levels, but are to its variations, i.e., fluxes. TTDs on the other hand strongly depend on the total amount of water stored in every CV. Using both data types for inference would therefore allow one to provide reasonable estimates of this quantity. Similarly, the estimation of water in the root and vadose zone can be improved.

In addition, Birkel and Soulsby (2015) highlight the temporal aspects of travel times on model calibration. They point out how the sampling frequency of the time series should match the expected travel times of the underlying process. Our results above revealed different timescales for different hydrological regimes, varying by almost an order of magnitude. Despite this heterogeneity, all travel times in our study remained within the range of months. Under such circumstances, a high-resolution measurement campaign with daily or even hourly intervals would not be necessary.

Although the above explanations provide only a limited perspective on the relationship between TTDs and model parameters, it can be said that the strong interlink between the travel-time behavior and outflow generation indicates the high information content of the former with respect to the latter. As a result, travel-time distributions should be regarded as highly informative for the calibration of hydrological models. As mentioned in the Introduction, McDonnell and Beven (2014) have made the case for the usefulness of TTDs for the parametrization of such models. The above presentations provide empirical support for this notion. 


\section{Conclusions}

In this study, we investigated the spatially distributed soilmoisture dynamics in the Nägelstedt catchment using traveltime distributions. The states and fluxes, needed for the derivation of the travel times, were numerically computed using the mesoscale Hydrological Model (mHM), which was calibrated against discharge data as well as using detailed data on soil properties, land cover and precipitation. We performed a statistical analysis of mean travel times to describe the soil response decoupled from the event-driven impact of precipitation.

Comparing the derived mean travel times for several modeling scales (spanning over 1 order of magnitude), we did not see any significant difference in their distribution. This indicates a general soundness of the parameterization scheme of mHM used for the calculation of the states and fluxes on the different modeling scales. Our analysis shows that precipitation, saturated soil moisture and potential evapotranspiration are strong statistical predictors of mean travel-time behavior. We also note that, on average, shorter mean travel times correspond to forested area and larger ones to crop/grassland, an observation that we linked to both correlations between forested and high-precipitation areas as well as the different water uptake mechanisms of trees vs. crop/grass.

We also investigated the travel-time behavior for different hydrological regimes, i.e., for dry and wet conditions (using soil moisture and precipitation as indicators). Our analysis revealed significantly different travel-time behavior for each of these regimes. Despite the strong heterogeneity of soil properties as well as (to a lesser extent) precipitation values, we could discriminate these regimes also in the resulting distribution of mean travel times.

Under dry conditions, we saw mean travel times having a pronounced bimodal distribution with long mean travel times and large variance. Such long travel times reveal the strong impact of baseflow on the generated outflow, whereas the large variance shows the variety of soil responses under dry conditions. Such conditions are therefore suited to inferring soil properties relating to baseflow generation. In addition, due to the large variance of soil responses, such conditions would allow the inference of the spatial origin of solutes found in discharge streams. Such inferences are, however, hampered by the long travel times involved. Not only are long time series needed, measurements must also be performed during such dry conditions.

Under wet conditions, we saw mean travel times having a unimodal distribution with shorter mean travel times and a smaller variance. This shorter travel times are caused by a larger influence of the slow and fast interflows on the total discharge behavior. As a result, TTDs derived under such conditions may be suited to inferring the parameters relating to these hydrological processes.
In the case of rainy months, which overlap with wet conditions to a significant degree, we saw a similar distribution of mean travel times, but with even shorter mean values. This indicates a stronger impact of fast interflow on the total discharge behavior. Such information can therefore be valuable for improving the parametrization of the fast interflow related processes.

It is important to emphasize that our results have been derived with respect to a single hydrological model, i.e., mHM, only. As a result, we also need to critically assess the limitations of this approach and its impact on the reliability of our conclusions. First, mHM treats the hydrological storage in every compartment as fully mixed. In the absence of additional information, we consequently assumed a uniform sampling scheme for the discharge generation from every $\mathrm{mHM}$ cell. This may have introduced errors in the age distribution of fluxes and therefore the travel-time behavior as discussed in Sect. 2.1. Due to the well-established ability of mHM to take sub-grid heterogeneity into account, we have confidence in the physical plausibility of the spatially explicit soil moisture states and fluxes. In the absence of, say, solute data, we have, however, to consider these assumptions as tentative and open to revision. The other limitation of our approach stems from the computational nature of our study, introducing a number of uncertainties. Like any hydrological model, mHM may suffer from three different sources of uncertainty: input uncertainty, structural uncertainty and parametric uncertainty. We would therefore like to assess their nature and potential impact on our results and conclusions. First, input uncertainty refers to the uncertainties inherent in the forcing of the model, i.e., precipitation. Our results have shown the strong impact of precipitation on travel-time behavior. It would therefore stand to reason that a strong impact of any uncertainty from precipitation propagates to the resulting travel-time behavior. However, we investigated mean behavior only, where time series from many months were averaged. We therefore consider possible contributions to our results to be minor. Next, structural uncertainty depends on the conceptual implementation of subsurface processes within mHM and our choices of different mHM compartments for our analysis. In Sect. 2.2, we discussed this issue by providing the rationales for, e.g., including the interflow components in our analysis. Finally, parameter analysis is probably the largest total source of uncertainty and several studies have recently investigated its impact on $\mathrm{mHM}$ output generation (Samaniego et al., 2013; Cuntz et al., 2015; Livneh et al., 2015). The studies show that, while the fluxes are typically well represented in mHM (Livneh et al., 2015), the overall soil moisture storage showed less accuracy, in particular during droughts Samaniego et al. (2013). For droughts, our results showed in general long travel times and pronounced soil-specific behavior with comparably lesser impact of precipitation. While we do not expect a major impact on the qualitative nature of these results, we should consider the quantitative aspect, i.e., the specific values for mean travel 
times, to be inconclusive. In general, we consider the uncertainty stemming from the storage estimate to be the most relevant due to having both comparably lower accuracy and the strong impact on overall travel-time behavior demonstrated above. This is exacerbated since the water content relevant for outflow generation may not be the same as the one relevant for travel-time behavior. Immobile water due to, e.g., dead-end pores, affects the latter but not the former. It is, however, this connection between the total water content and the resulting travel-time behavior that makes the use of TTDs an important tool for a better calibration of hydrological models.

As an outlook, we can say that, having established a comprehensive description for the storage and release of water in the investigated catchment, the natural next step is the integration of reactive solute transport. As demonstrated by, e.g., Botter et al. (2010), the concept of travel-time distributions can directly be adapted to account for the transport of both conservative and reactive solutes. This extension would facilitate the comparison of our predictions with the wealth of data that has been and continues to be collected within the AquaDiva center at the Hainich Critical Zone Exploratory (Küsel et al., 2016). Thereby, we will be able to test our predictions by virtue of a large data set as well as initiate the collection of additional new data.

\section{Data availability}

For the production of the simulations that were used in this study, we used the mesoscale Hydrological Model with several forcings. The model itself is properly referenced in the paper, whereas the providers of the forcings (digital elevation, rain intensity, solar radiation, soil types, etc.) are referenced in the Acknowledgements. Both the raw data, i.e., the results of the mHM simulations, as well as the post-processed data, can be solicited from the corresponding author. 


\section{Appendix A: Forward and backward formulation of travel times}

Both the forward and backward formulations for TTDs can be derived from Eq. (1) by additionally associating each term with its distribution. Therefore, we get

$$
\begin{aligned}
& \frac{\mathrm{d}}{\mathrm{d} t}\left[S(t) p_{\mathrm{S}}(T, t)\right]=J(t) p_{\mathrm{J}}(T, t)-\mathrm{ET}(t) p_{\mathrm{ET}}(T, t) \\
& \quad-Q(t) p_{\mathrm{Q}}(T, t) .
\end{aligned}
$$

Here $T$ is a placeholder for either the age or life expectancy of the water parcel. The total derivative in Eq. (A1) can be reformulated using the material derivative, so

$$
\begin{aligned}
& \left(\frac{\partial}{\partial t}+\frac{\mathrm{d}}{\mathrm{d} t} T \frac{\partial}{\partial T}\right)\left[S(t) p_{\mathrm{S}}(t, T)\right]=J(t) p_{\mathrm{J}}(t, T) \\
& -\operatorname{ET}(t) p_{\mathrm{ET}}(t, T)-Q(t) p_{\mathrm{Q}}(t, T) .
\end{aligned}
$$

Equation (A2) is the general partial differential equation (PDE) describing the time evolution of the age of the water in the CV. It is worthwhile noting that there is a significant inconsistency in the literature with respect to this equation. Botter et al. (2011) discuss the backward formulation of Eq. (A2), while referring to it as the Master Equation (ME). This is certainly justified given that the ME is describing the time evolution of the PDF of any Markov process, i.e., a stochastic process that is local in (chronological) time. This condition is true for Eq. (A2). In addition, Eq. (A2) is not only local with respect to chronological time $t$, but also with respect to the travel time $T$. Interpreting $T$ as $x$, it becomes obvious that Eq. (A2) is analogous to the much simpler Fokker-Planck equation or, since there is no "diffusion", the even simpler advection-reaction equation. On the other hand, Porporato and Calabrese (2015) are careful to trace this equation back to the seminal work of both M'Kendrick (1925) and von Förster (1959) in population dynamics. Consequently, they call this equation the McKendrick-von Förster (MKVF) equation.
One problem with Eqs. (A1) and (A2) is the lack of closure; i.e., $p_{\mathrm{S}}(T, t), p_{\mathrm{J}}(T, t), p_{\mathrm{ET}}(T, t)$ and $p_{\mathrm{Q}}(T, t)$ are different variables. The solution to this problem is the formulation and/or derivation of a dependency, i.e., closure, between the storage and the fluxes through

$p_{\mathrm{F}}(T, t)=\omega(T, t) p_{\mathrm{S}}(T, t)$.

This closure function $\omega(T, t)$ must follow some properties to ensure the normality of both $p_{\mathrm{S}}(T, t)$ and $p_{\mathrm{F}}(T, t)$, with the latter being the PDF of a flux, i.e., effective precipitation, evapotranspiration or discharge. These closure functions are called StorAge Selection (SAS) functions in the literature (Rinaldo et al., 2015). Several different formulations exist, with the one given above being based on the work of Botter (2012).

The shape of the SAS function determines the preference of the fluxes, e.g., discharge, for several ages of the water stored in the CV. In the backward formulation, a flat function would correspond to no preference with respect to age, a monotonously decreasing function would correspond to a preference for younger water and a monotonously increasing function would correspond to a preference for older water. 
Competing interests. The authors declare that they have no conflict of interest.

Acknowledgements. We would like to thank the two reviewers and the editor for their helpful comments as well as Heather Savoy for proofreading the manuscript. The study was financially supported by the Deutsche Forschungsgemeinschaft via Sonderforschungsbereich CRC 1076 AquaDiva. In addition, Matthias Zink was financed by HGF-EDA. We furthermore kindly acknowledge our data providers: the German Weather Service (DWD), the Joint Research Center of the European Commission, the European Environmental Agency, the Federal Institute for Geosciences and Natural Resources (BGR), the European Water Archive, the Global Runoff Data Centre, project CarboEuropeIP (EU-FP6) as well as Axel Don for the provision of eddy-covariance data.

The article processing charges for this open-access

publication were covered by a Research

Centre of the Helmholtz Association.

Edited by: M. Hrachowitz

Reviewed by: H. McMillan and one anonymous referee

\section{References}

Almorox, J., Quej, V. H., and Martí, P.: Global performance ranking of temperature-based approaches for evapotranspiration estimation considering Köppen climate classes, J. Hydrol., 528, 514522, doi:10.1016/j.jhydrol.2015.06.057, 2015.

Benettin, P., Rinaldo, A., and Botter, G.: Kinematics of age mixing in advection-dispersion models, Water Resour. Res., 49, 85398551, doi:10.1002/2013WR014708, 2013.

Benettin, P., Rinaldo, A., and Botter, G.: Tracking residence times in hydrological systems: forward and backward formulations, Hydrol. Process., 29, 5203-5213, doi:10.1002/hyp.10513, 2015a.

Benettin, P., Kirchner, J. W., Rinaldo, A., and Botter, G.: Modeling chloride transport using travel time distributions at plynlimon, wales, Water Resour. Res., 51, 3259-3276, doi:10.1002/2014WR016600, 2015b.

Bergström, S.: Computer Models of Watershed Hydrology, in: The HBV Model, edited by: Singh, V. P., Water Resources Publications, LLC, USA, 443-476, 1995.

Bertuzzo, E., Thomet, M., Botter, G., and Rinaldo, A.: Catchmentscale herbicides transport: Theory and application, Adv. Water Resour., 52, 232-242, doi:10.1016/j.advwatres.2012.11.007, 2013.

Birkel, C. and Soulsby, C.: Advancing tracer-aided rainfall-runoff modelling: a review of progress, problems and unrealised potential, Hydrol. Process., 29, 5227-5240, doi:10.1002/hyp.10594, 2015.

Botter, G.: Catchment mixing processes and travel time distributions, Water Resour. Res., 48, W05545, doi:10.1029/2011WR011160, 2012.

Botter, G., Bertuzzo, E., and Rinaldo, A.: Transport in the hydrologic response: Travel time distributions, soil moisture dynamics, and the old water paradox, Water Resour. Res., 46, W03514, doi:10.1029/2009WR008371, 2010.
Botter, G., Bertuzzo, E., and Rinaldo, A.: Catchment residence and travel time distributions: The master equation, Geophys. Res. Lett., 38, L11403, doi:10.1029/2011GL047666, 2011.

Broxton, P. D., Troch, P. A., and Lyon, S. W.: On the role of aspect to quantify water transit times in small mountainous catchments, Water Resour. Res., 45, W08427, doi:10.1029/2008WR007438, 2009.

Cardenas, M. B.: Potential contribution of topography-driven regional groundwater flow to fractal stream chemistry: Residence time distribution analysis of tóth flow, Geophys. Res. Lett., 34, L05403, doi:10.1029/2006GL029126, 2007.

Cornaton, F. and Perrochet, P.: Groundwater age, life expectancy and transit time distributions in advective-dispersive systems: 1. generalized reservoir theory, Adv. Water Resour., 29, 12671291, doi:10.1016/j.advwatres.2005.10.009, 2006a.

Cornaton, F. and Perrochet, P.: Groundwater age, life expectancy and transit time distributions in advective-dispersive systems; 2. reservoir theory for sub-drainage basins, Adv. Water Resour., 29, 1292-1305, doi:10.1016/j.advwatres.2005.10.010, 2006 b.

Cuntz, M., Mai, J., Zink, M., Thober, S., Kumar, R., Schäfer, D., Schrön, M., Craven, J., Rakovec, D., Spieler, D., Prykhodko, V., Dalmasso, G., Musuuza, J., Langenberg, B., Attinger, S., and Samaniego, L.: Computationally inexpensive identification of noninformative model parameters by sequential screening, Water Resour. Res., 51, 6417-6441, doi:10.1002/2015WR016907, 2015.

Dagan, G.: Statistical theory of groundwater flow and transport: Pore to laboratory, laboratory to formation, and formation to regional scale, Water Resour. Res., 22, 120S-134S, doi:10.1029/WR022i09Sp0120S, 1986.

Dagan, G.: Flow and Transport in Porous Formations, Springer, Berlin Heidelberg, 1989.

Daly, E. and Porporato, A.: Impact of hydroclimatic fluctuations on the soil water balance, Water Resour. Res., 42, W06401, doi:10.1029/2005WR004606, 2006.

Danckwerts, P.: Continuous flow systems, Chem. Eng. Sci., 2, 1-13, doi:10.1016/0009-2509(53)80001-1, 1953.

Duffy, C. J.: Dynamical modelling of concentration-agedischarge in watersheds, Hydrol. Process., 24, 1711-1718, doi:10.1002/hyp.7691, 2010.

Dunn, S. M., Darling, W. G., Birkel, C., and Bacon, J. R.: The role of groundwater characteristics in catchment recovery from nitrate pollution, Hydrol. Res., 43, 560-575, doi:10.2166/nh.2012.020, 2012.

Fan, Y.: Groundwater in the earth's critical zone: Relevance to largescale patterns and processes, Water Resour. Res., 51, 3052-3069, doi:10.1002/2015WR017037, 2015.

Federal Institute for Geosciences and Natural Resources (BGR): Digital soil map of Germany 1: 1000000 (BUEK 1000), Tech. rep., Hannover, Berlin, Germany, 1998.

Fenicia, F., Wrede, S., Kavetski, D., Pfister, L., Hoffmann, L., Savenije, H. H. G., and McDonnell, J. J.: Assessing the impact of mixing assumptions on the estimation of streamwater mean residence time, Hydrol. Process., 24, 1730-1741, doi:10.1002/hyp.7595, 2010.

Hargreaves, G. H. and Samani, Z. A.: Reference crop evapotranspiration from temperature, Appl. Eng. Agr., 1, 96-99, 1985.

Harman, C. J.: Time-variable transit time distributions and transport: Theory and application to storage-dependent transport 
of chloride in a watershed, Water Resour. Res., 51, 1-30, doi:10.1002/2014WR015707, 2015.

Hrachowitz, M., Soulsby, C., Tetzlaff, D., Dawson, J. J. C., and Malcolm, I. A.: Regionalization of transit time estimates in montane catchments by integrating landscape controls, Water Resour. Res., 45, W05421, doi:10.1029/2008WR007496, 2009.

Hrachowitz, M., Savenije, H., Bogaard, T. A., Tetzlaff, D., and Soulsby, C.: What can flux tracking teach us about water age distribution patterns and their temporal dynamics?, Hydrol. Earth Syst. Sci., 17, 533-564, doi:10.5194/hess-17-533-2013, 2013.

Hrachowitz, M., Fovet, O., Ruiz, L., and Savenije, H. H. G.: Transit time distributions, legacy contamination and variability in biogeochemical $1 / f(\alpha)$ scaling: how are hydrological response dynamics linked to water quality at the catchment scale?, Hydrol. Process., 29, 5241-5256, doi:10.1002/hyp.10546, 2015.

Kitanidis, P. K.: Persistent questions of heterogeneity, uncertainty, and scale in subsurface flow and transport, Water Resour. Res., 51, 5888-5904, doi:10.1002/2015WR017639, 2015.

Kumar, R., Samaniego, L., and Attinger, S.: The effects of spatial discretization and model parameterization on the prediction of extreme runoff characteristics, J. Hydrol., 392, 54-69, doi:10.1016/j.jhydrol.2010.07.047, 2010.

Kumar, R., Samaniego, L., and Attinger, S.: Implications of distributed hydrologic model parameterization on water fluxes at multiple scales and locations, Water Resour. Res., 49, 360-379, doi:10.1029/2012WR012195, 2013a.

Kumar, R., Livneh, B., and Samaniego, L.: Toward computationally efficient large-scale hydrologic predictions with a multiscale regionalization scheme, Water Resour. Res., 49, 57005714, doi:10.1002/wrcr.20431, 2013b.

Küsel, K., Totsche, K. U., Trumbore, S. E., Lehmann, R., Steinhäuser, C., and Herrmann, M.: How deep can surface signals be traced in the critical zone? Merging biodiversity with biogeochemistry research in a central German Muschelkalk landscape, Front. Earth Sci., 4, 32, doi:10.3389/feart.2016.00032, 2016.

Livneh, B., Kumar, R., and Samaniego, L.: Influence of soil textural properties on hydrologic fluxes in the mississippi river basin, Hydrol. Process., 29, 4638-4655, doi:10.1002/hyp.10601, 2015.

Małloszewski, P. and Zuber, A.: Determining the turnover time of groundwater systems with the aid of environmental tracers, J. Hydrol., 57, 207-231, doi:10.1016/0022-1694(82)901470, 1982.

McDonnell, J. J. and Beven, K.: Debates - The future of hydrological sciences: A (common) path forward? A call to action aimed at understanding velocities, celerities and residence time distributions of the headwater hydrograph, Water Resour. Res., 50, 5342-5350, doi:10.1002/2013WR015141, 2014.

McGuire, K. J. and McDonnell, V: Tracer advances in catchment hydrology, Hydrol. Process., 29, 5135-5138, doi:10.1002/hyp.10740, 2015.

McGuire, K. J., McDonnell, J. J., Weiler, M., Kendall, C., McGlynn, B. L., Welker, J. M., and Seibert, J.: The role of topography on catchment-scale water residence time, Water Resour. Res., 41, W05002, doi:10.1029/2004WR003657, 2005.

McMillan, H., Tetzlaff, D., Clark, M., and Soulsby, C.: Do timevariable tracers aid the evaluation of hydrological model structure? a multimodel approach, Water Resour. Res., 48, W05501, doi:10.1029/2011WR011688, 2012.
M'Kendrick, L.-C. A. G.: Applications of mathematics to medical problems, Proc. Edinburgh Math. Soc., 44, 98-130, 1925.

Niemi, A. J.: Residence time distributions of variable flow processes, Int. J. Appl. Radiat. Isotopes, 28, 855-860, doi:10.1016/0020-708X(77)90026-6, 1977.

Porporato, A. and Calabrese, S.: On the probabilistic structure of water age, Water Resour. Res., 51, 3588-3600, doi:10.1002/2015WR017027, 2015.

Rakovec, O., Kumar, R., Mai, J., Cuntz, M., Thober, S., Zink, M., Attinger, S., Schäfer, D., Schrön, M., and Samaniego, L.: Multiscale and multivariate evaluation of water fluxes and states over European river basins, J. Hydrometeorol., 17, 287-307, doi:10.1175/JHM-D-15-0054.1, 2016.

Rinaldo, A. and Marani, A.: Basin scale model of solute transport, Water Resour. Res., 23, 2107-2118, doi:10.1029/WR023i011p02107, 1987.

Rinaldo, A., Marani, A., and Bellin, A.: On mass response functions, Water Resour. Res., 25, 1603-1617, doi:10.1029/WR025i007p01603, 1989.

Rinaldo, A., Botter, G., Bertuzzo, E., Uccelli, A., Settin, T., and Marani, M.: Transport at basin scales: 1. theoretical framework, Hydrol. Earth Syst. Sci., 10, 19-29, doi:10.5194/hess-10-192006, 2006.

Rinaldo, A., Beven, K. J., Bertuzzo, E., Nicotina, L., Davies, J., Fiori, A., Russo, D., and Botter, G.: Catchment travel time distributions and water flow in soils, Water Resour. Res., 47, W07537, doi:10.1029/2011WR010478, 2011.

Rinaldo, A., Benettin, P., Harman, C. J., Hrachowitz, M., McGuire, K. J., van der Velde, Y., Bertuzzo, E., and Botter, G.: Storage selection functions: A coherent framework for quantifying how catchments store and release water and solutes, Water Resour. Res., 51, 4840-4847, doi:10.1002/2015WR017273, 2015.

Rubin, Y.: Applied Stochastic Hydrogeology, Oxford University Press, Oxford, USA, 416 pp., 2003.

Samani, Z. A.: Estimating solar radiation and evapotranspiration using minimum climatological data, J. Irrig. Drain. Eng., 126, 265 267, doi:10.1061/(ASCE)0733-9437(2000)126:4(265), 2000.

Samaniego, L., Kumar, R., and Attinger, S.: Multiscale parameter regionalization of a grid-based hydrologic model at the mesoscale, Water Resour. Res., 46, W05523, doi:10.1029/2008WR007327, 2010a.

Samaniego, L., Bárdossy, A., and Kumar, R.: Streamflow prediction in ungauged catchments using copula-based dissimilarity measures, Water Resour. Res., 46, W02506, doi:10.1029/2008WR007695, 2010b.

Samaniego, L., Kumar, R., and Zink, M.: Implications of parameter uncertainty on soil moisture drought analysis in germany, J. Hydrometeorol., 14, 47-68, doi:10.1175/JHM-D-12-075.1, 2013.

Sayama, T. and McDonnell, J. J.: A new time-space accounting scheme to predict stream water residence time and hydrograph source components at the watershed scale, Water Resour. Res., 45, W07401, doi:10.1029/2008WR007549, 2009.

Tetzlaff, D., Malcolm, I., and Soulsby, C.: Influence of forestry, environmental change and climatic variability on the hydrology, hydrochemistry and residence times of upland catchments, J. Hydrol., 346, 93-111, doi:10.1016/j.jhydrol.2007.08.016, 2007.

Tetzlaff, D., Seibert, J., McGuire, K. J., Laudon, H., Burns, D. A., Dunn, S. M., and Soulsby, C.: How does landscape structure influence catchment transit time across dif- 
ferent geomorphic provinces?, Hydrol. Process., 23, 945-953, doi:10.1002/hyp.7240, 2009.

Tetzlaff, D., Soulsby, C., Hrachowitz, M., and Speed, M.: Relative influence of upland and lowland headwaters on the isotope hydrology and transit times of larger catchments, J. Hydrol., 400, 438-447, doi:10.1016/j.jhydrol.2011.01.053, 2011.

Thober, S., Kumar, R., Sheffield, J., Mai, J., and Schäfer, D., and Samaniego, L.: Seasonal Soil Moisture Drought Prediction over Europe Using the North American Multi-Model Ensemble (NMME), J. Hydrometeorol., 16, 2329-2344, 2015.

van der Velde, Y., Torfs, P. J. J. F., van der Zee, S. E. A. T. M., and Uijlenhoet, R.: Quantifying catchment-scale mixing and its effect on time-varying travel time distributions, Water Resour. Res., 48, W06536, doi:10.1029/2011WR011310, 2012.

Vereecken, H., Huisman, J. A., Franssen, H.-J. H., Brueggemann, N., Bogena, H. R., Kollet, S., Javaux, M., van der Kruk, J., and Vanderborght, J.: Soil hydrology: Recent methodological advances, challenges, and perspectives, Water Resour. Res., 51, 2616-2633, doi:10.1002/2014WR016852, 2015. von Förster, H.: Some remarks on changing populations, in: The Kinetics of Cellular Proliferation, edited by: Stohlman, F., Grune and Stratton, New York, NY, 382-407, 1959.

Wang, K. and Dickinson, R. E.: A review of global terrestrial evapotranspiration: Observation, modeling, climatology, and climatic variability, Rev. Geophys., 50, RG2005, doi:10.1029/2011RG000373, 2012.

Windhorst, D., Kraft, P., Timbe, E., Frede, H.-G., and Breuer, L.: Stable water isotope tracing through hydrological models for disentangling runoff generation processes at the hillslope scale, Hydrol. Earth Syst. Sci., 18, 4113-4127, doi:10.5194/hess-18-41132014.

Zacharias, S. and Wessolek, G.: Excluding organic matter content from pedotransfer predictors of soil water retention, Soil Sci. Soc. Am. J., 71, 43-50, 2007. 